\title{
Anti-proliferative activity and cell metabolism of hydroxycinnamic acids in human colon adenocarcinoma cell lines
}

Serena Martini, Angela Conte, Davide Tagliazucchi*

Department of Life Sciences, University of Modena and Reggio Emilia, Via Amendola 2, 42100

Reggio Emilia, Italy

* Corresponding author. Tel.: +39-0522-522060; fax: +39-0522-522053

E-mail address: davide.tagliazucchi@unimore.it (D. Tagliazucchi) 


\section{Abstract}

2 In this study, we investigated the anti-proliferative activity and the stability and metabolic fate of

3 the main dietary hydroxycinnamates, using two colonic adenocarcinoma cell models (Caco-2 and

4 SW480). Di-hydro-caffeic and di-hydro-ferulic acids were the most effective against cell

5 proliferation in both cell lines with $\mathrm{IC}_{50}$ values of $71.7 \pm 1.1$ and $83.1 \pm 1.1 \mu \mathrm{mol} / \mathrm{L}$, respectively

$6 \quad(P<0.05)$ in Caco-2. At $200 \mu \mathrm{mol} / \mathrm{L}$, caffeic and ferulic acids inhibited SW480 proliferation by 40.8

$7 \pm 1.6$ and $59.9 \pm 1.3 \%$, respectively. Hydroxycinnamic acids with a catechol-type structure were

8 degraded in Caco-2 cell medium resulting in the production of $\mathrm{H}_{2} \mathrm{O}_{2}$. Intracellular Caco-2 UDP-

9 glucuronosyltransferases and catechol- $O$-methyltransferases were able to form glucuronide and

10 methyl conjugates. However, only the sulphate conjugates were detected after incubation with

11 SW480. In addition, simple hydroxycinnamates were released from quinic and aspartic-conjugates.

12 The remarkable effect of di-hydro-caffeic and di-hydro-ferulic acids against cell proliferation is of

13 paramount importance since these compounds are the main metabolites detectable at colonic level.

14

15 Keywords: mass spectrometry, metabolism, anti-proliferative activity, phenolic compounds, colon

16 cancer 


\section{Introduction}

18 Dietary polyphenols have gained increasing interest because of their numerous biological effects such as free-radical scavenging and metal chelation activities, modulation of enzymatic activity, inhibition of cellular proliferation, and altering signal transduction pathways. ${ }^{1-2}$ In this context, emerging evidence is confirming the ever-increasing importance of hydroxycinnamic acids in the prevention of cardiovascular and other chronic diseases. ${ }^{3}$ Hydroxycinnamic acids are widespread dietary components found, for instance, in coffee, cherries, apples, chocolate, yerba mate and several vegetables and herbs. ${ }^{3}$ The interest in these compounds is related to their beneficial health effects in vivo. ${ }^{4-5}$ However, the extent of their protective effect depends on their bioavailability after intestinal absorption, metabolism, and subsequent interaction with target tissues. ${ }^{1}$

More interestingly, highly and regularly consumed foods rich in hydroxycinnamic acids are particularly intriguing for their potential beneficial effects in the gastro-intestinal tract where hydroxycinnamic acids can reach concentrations of hundreds of $\mu \mathrm{mol} / \mathrm{L} .^{3,6,7}$ To this purpose, recent epidemiological studies on colorectal cancer risk have demonstrated some evidence of protection

31 after ingestion of hydroxycinnamates-rich foods or beverages such as coffee and apples. ${ }^{8-10}$ 32 Furthermore, dark chocolate and cherry intake have been shown to inhibit tumour development in 33 azoxymethane-induced colonic cancer in rats. ${ }^{11-12}$ Recently, our research group thoroughly investigated the effect of in vitro gastro-intestinal digestion on the bioaccessibility of phenolic compounds from two different cherry cultivars (Celeste and Durone Nero I) and three different types of dark chocolates. ${ }^{13-14}$ Phenolic acids and especially hydroxycinnamic acids showed the highest bioaccessibility in all the food matrices. The highest release after incubation of cherries with digestive fluids was found for coumaroylquinic acids,

39 followed by feruloylquinic and caffeoylquinic acids; a similar trend was seen for the conjugate forms of hydroxycinnamic acids with aspartic acid after in vitro digestion of dark chocolate. We

41 also demonstrated that hydroxycinnamic acids tended to accumulate in cell media suggesting a 
possible role in the anti-proliferative activity of in vitro digested cherry and dark chocolate against colon adenocarcinoma cell lines. ${ }^{13-14}$

The stability of phenolic compounds in cell culture media as well as their cellular metabolism are two aspects to be critically addressed when testing their anti-proliferative activity. Their instability in cell media may hinder their biological activity, severely changing the concentrations and/or the chemical structures of the tested compounds. ${ }^{15}$ Indeed, the cellular metabolism of phenolic compounds may evidently alter the bioactivity of the tested molecules. ${ }^{16}$ Therefore, to get a complete picture of the scenario, the stability of the parent compounds and the formation of their cellular metabolites should be evaluated.

Thus, the aim of this work was to study the stability and the cell metabolism of cinnamic acid, the main dietary hydroxycinnamic acids (o-coumaric acid, $p$-coumaric acid, caffeic acid, ferulic acid and 5-O-caffeoylquinic acid) as well as the two most important colonic metabolites (di-hydrocaffeic acid and di-hydro ferulic acid) using Caco-2 and SW480 cell lines. Moreover, coumaroylquinic acids and hydroxycinnamoyl aspartates extracted from sweet cherry (Celeste cultivar) and dark chocolate, respectively, were also included in the analysis (Figure 1). In addition, the anti-proliferative effect against two models of human colonic adenocarcinoma cell lines (Caco-2 and SW480) was assessed. The main metabolic pathways were drawn through the detection and identification of newly-formed metabolites by LC-ESI-IT-MS/MS analysis after $24 \mathrm{~h}$ of incubation.

\section{Materials and methods}

\subsection{Chemicals}

Phenolic compound standards (o-coumaric acid, $p$-coumaric acid, caffeic acid, ferulic acid, dihydro-caffeic acid, di-hydro ferulic acid, cinnamic acid and 5-O-caffeoylquinic acid) and reagents for analytical determinations were purchased from Sigma (Milan, Italy). Methanol, formic acid and acetonitrile were obtained from Carlo Erba (Milan, Italy). All MS/MS reagents were from Bio-Rad 
(Hercules, CA, U.S.A.). All the materials and chemicals for cell culture were from VWR International (Milan, Italy). MTS cell proliferation assay kit was purchased from Promega (Milan, Italy). Solid phase extraction (SPE) column (C18, $50 \mu \mathrm{m}, 60 \AA$, $500 \mathrm{mg})$ were supplied by Waters (Milan, Italy).

\subsection{Hydroxycinnamoyl aspartates and coumaroylquinic acids enriched extracts preparation}

Coumaroylquinic acids and hydroxycinnamoyl aspartates enriched fractions were extracted from in vitro digested sweet cherry (Celeste cultivar) and dark chocolate, respectively, following the protocol reported in Tagliazucchi et al. with some modifications. ${ }^{17}$ The two food matrices were digested as reported in Martini et al. ${ }^{14}$ Firstly, SPE column were preconditioned with $4 \mathrm{~mL}$ of methanol, followed by $5 \mathrm{~mL}$ of water adjusted to $\mathrm{pH} 7.4$ with $\mathrm{NaOH} 1 \mathrm{~mol} / \mathrm{L}$. Then, $1 \mathrm{~mL}$ of the in vitro digested fractions were passed through the pre-conditioned $\mathrm{C}-18$ column to adsorb neutral phenolic compounds. Non-adsorbed phenolic acids were washed with $3 \mathrm{~mL}$ of water at $\mathrm{pH} 7$. After acidification of the column with $5 \mathrm{~mL}$ of acidified water (containing $0.1 \%$ of formic acid) the adsorbed phenolic compounds were eluted with $4 \mathrm{~mL}$ of an acetonitrile solution (10\% acetonitrile and $90 \%$ acidified water). During elution with acetonitrile, four fractions of $1 \mathrm{~mL}$ each were collected separately. These fractions were called ACN1, ACN2, ACN3 and ACN4. The remaining bound compounds were then eluted with $3 \mathrm{~mL}$ of acidified methanol.

Three digested fractions for each food matrix were extracted in triplicate.

Fractions collected from SPE were analyzed by using mass spectrometry to identify phenolic compounds. Firstly, all of the fractions $(2 \mu \mathrm{L})$ were directly injected on an ion trap mass spectrometer coupled with an electrospray ionizator (ESI). ESI operating conditions are reported in Martini et al. ${ }^{18}$ The direct infusion experiments were carried out to detect the $\mathrm{m} / \mathrm{z}$ signals present in each fraction. Specific fractions containing the $\mathrm{m} / \mathrm{z}$ signals corresponding to coumaroylquinic acids ( $\mathrm{m} / \mathrm{z}$ 337) and hydroxycinnamoyl aspartates $(\mathrm{m} / \mathrm{z}$ 278, 294 and 308 for coumaroyl-aspartate, 
caffeoyl-aspartate and feruloyl-aspartate, respectively) were analyzed by liquid chromatography electrospray ionization ion trap mass spectrometry (LC-ESI-IT-MS/MS) on HPLC Agilent 1200 Series system equipped with a C18 column (HxSil C18 Reversed phase, 250×4.6 mm, $5 \mu \mathrm{m}$ particle size, Hamilton Company, Reno, Nevada, USA). The mobile phase composition was (A) $\mathrm{H}_{2} \mathrm{O} /$ formic acid (99:1, v/v) and (B) acetonitrile/formic acid (99:1, v/v). After 0.5 min at $4 \% \mathrm{~B}$, the gradient linearly ramped up to $30 \% \mathrm{~B}$ in $60 \mathrm{~min}$. The mobile phase composition was raised up to $100 \% \mathrm{~B}$ in $1 \mathrm{~min}$ and maintained for $5 \mathrm{~min}$ in order to wash the column before returning to the initial condition. The flow rate was set at $1 \mathrm{~mL} / \mathrm{min}$. The samples were injected in the amount of 40 $\mu \mathrm{L}$. After passing through the column, the eluate was split and $0.4 \mathrm{~mL} / \mathrm{min}$ were directed to an Agilent 6300 ion trap mass spectrometer. Identification of phenolic compounds in all samples was carried out using full scan and data-dependent $\mathrm{MS}^{2}$ scanning from $m / z, 100$ to 1700 . MS operating conditions, limits of detection (LOD) and limits of quantification (LOQ) for the different standards are reported in Martini et al. ${ }^{18}$ Coumaroylquinic acids and coumaroyl-aspartate were quantified as coumaric acid equivalent whereas caffeoyl-aspartate and feruloyl-aspartate were quantified as caffeic and ferulic acids equivalents, respectively.

Results were expressed as $\mu \mathrm{mol} / \mathrm{L}$ of standard equivalents.

\subsection{Cell cultures and anti-proliferative activity}

Human adenocarcinoma Caco-2 cells were cultured in Dulbecco's Modified Eagle's Medium (DMEM) supplemented with 10\% fetal bovine serum (FBS), $1 \%$ antibiotic mix (streptomycin and penicillin) and $2 \mathrm{mmol} / \mathrm{L}$ L-glutamine. Human adenocarcinoma SW480 cells were cultured in Leibowitz medium (L-15) supplemented with 10\% FBS, $1 \%$ antibiotic mix (streptomycin and penicillin) and $2 \mathrm{mmol} / \mathrm{L} \mathrm{L-glutamine.} \mathrm{Cells} \mathrm{were} \mathrm{maintained} \mathrm{at} 37^{\circ} \mathrm{C}$ in a humidified atmosphere of $5 \% \mathrm{CO}_{2}$. 
116 Cells were seeded at $4 \times 10^{3} / \mathrm{cm}^{2}$ and $8 \times 10^{3} / \mathrm{cm}^{2}$ for Caco-2 and SW480, respectively, in 96-well

117 plates for $24 \mathrm{~h}$ to allow cell adhesion to the bottom of the wells.

118 The anti-proliferative activity was assayed by a colorimetric method for the sensitive quantification

119 of viable cells, using MTS assay kit on Caco-2 and SW480 cell lines as reported in Martini et al. ${ }^{16}$

120 Coumaric acids ( $o$ - and $p$-isomers), caffeic, ferulic, di-hydro-caffeic, di-hydro ferulic, 5- $O$ -

121 caffeoylquinic and cinnamic acids standards were dissolved in methanol at concentration of 20

$122 \mathrm{mmol} / \mathrm{l}$ and then diluted in both the two cell lines culture media (Caco-2 and SW480) at a final

123 concentration of $200 \mu \mathrm{mol} / \mathrm{L}$. A control solution of $1 \%$ methanol in cell medium was used as $100 \%$

124 proliferation. Coumaroylquinic acids and hydroxycinnamoyl aspartates enriched fractions from SPE

125 were diluted twice in both the two cell lines culture media and the $\mathrm{pH}$ was brought to 7.4 with

126 concentrated $\mathrm{NaOH}$. An appropriate control solution consisting of the elution phase of SPE (10\%

127 acetonitrile and $90 \%$ acidified water containing $0.1 \%$ of formic acid) diluted twice in the cell

128 medium and bring to $\mathrm{pH} 7.4$ was used as $100 \%$ proliferation. $100 \mu \mathrm{L}$ of each sample were added to

129 the cell plates and incubated for $24 \mathrm{~h}$. At the end of the treatment, the media were collected for

130 detection of newly-formed metabolites and $180 \mu \mathrm{L}$ of fresh culture medium and $20 \mu \mathrm{L}$ of MTS

131 reagent were added to each well. After $4 \mathrm{~h}$ of incubation at $37^{\circ} \mathrm{C}$, the absorbance was measured at

132 the wavelength of $490 \mathrm{~nm}$ using a microplate reader and results were expressed as percentage of

133 inhibition of cell proliferation. When possible, the $\mathrm{IC}_{50}$ values, representing concentration of

134 compound required to inhibit 50\% cell proliferation, were determined by incubating cells with

135 different concentrations of the phenolic compound. $\mathrm{IC}_{50}$ values were expressed as $\mu$ mol of phenolic

136 compound/L and were determined using nonlinear regression analysis and fitting the data with the

$137 \log$ (inhibitor) vs. response model generated by GraphPad Prism 6.0 (GraphPad Software, San

138 Diego, CA, USA).

139

140

\subsection{Stability of hydroxycinnamic acids in cell culture media}


141 Hydroxycinnamic acids were diluted to $200 \mu \mathrm{mol} / \mathrm{L}$ with DMEM or L-15 before testing.

142 Coumaroylquinic acids and hydroxycinnamoyl aspartates enriched fractions were diluted twice in 143 both the two cell lines culture media. $100 \mu \mathrm{L}$ of the diluted hydroxycinnamic acids solution were 144 incubated at $37^{\circ} \mathrm{C}$ in $5 \% \mathrm{CO}_{2}$ for $24 \mathrm{~h}$ in 96 -well plates. At the end of incubation, the samples were 145 collected from the plates and analyzed by LC-MS/MS analysis as reported in section 2.5.

\subsection{Liquid chromatography coupled to mass spectrometry (LC-MS/MS) analysis of cell media}

148 Cell culture supernatants as well as cell-free media containing hydroxycinnamic acids were 149 collected after $24 \mathrm{~h}$ to test the stability of hydroxycinnamic acids in cell culture media and the 150 presence of newly-formed metabolites. Cell media were extracted according to Sala et al. and 151 analyzed using the same LC-ESI-IT-MS/MS system as reported above, with an injection volume of $15240 \mu \mathrm{L}$ and elution flow rate of $1 \mathrm{~mL} / \mathrm{min} .{ }^{19}$ The mobile phase composition, the gradient and MS 153 operating conditions are the same as reported in Martini et al. ${ }^{20}$

\subsection{Measurement of the concentration of $\mathrm{H}_{2} \mathrm{O}_{2}$ in cell media}

156 The generation of $\mathrm{H}_{2} \mathrm{O}_{2}$ after $24 \mathrm{~h}$ of incubation of hydroxycinnamic acids with cell-free media was 157 assessed with the FOX assay as reported in Martini et al. ${ }^{20}$ The concentration of $\mathrm{H}_{2} \mathrm{O}_{2}$ was 158 calculated from a standard curve obtained with different concentrations of $\mathrm{H}_{2} \mathrm{O}_{2}$.

\subsection{Statistic}

161 All data are presented as mean \pm SD for three replicates for each prepared sample. One-way 162 analysis of variance (one-way ANOVA) with Tukey's post-hoc test was applied using Graph Pad 163 prism 6.0 (GraphPad software, San Diego, CA, U.S.A.). The differences were considered 164 significant with $P<0.05$. 


\section{Results}

\subsection{Anti-proliferative activity of hydroxycinnamic acid standards and colonic metabolites}

168 Treatment for $24 \mathrm{~h}$ with $p$-coumaric, $o$-coumaric, cinnamic and 5-caffeoylquinic (5-CQA) acids at $200 \mu \mathrm{mol} / \mathrm{L}$ did not affect cell proliferation in both colon adenocarcinoma cell lines (Table 1).

Caffeic and ferulic acids showed some effects, decreasing cell proliferation of SW480 cancer cells after $24 \mathrm{~h}$ treatment at $200 \mu \mathrm{mol} / \mathrm{L}$. The anti-proliferate activity of ferulic acid against SW480 cell line was significantly higher than that of caffeic acid $(P<0.05)$ however, neither of the compounds reduced cell proliferation in Caco-2 cells. The microbial metabolites di-hydro-caffeic (DHC) and di-hydro-ferulic (DHF) acids were able to notably reduce cell proliferation in both the cell lines. The effect was significantly higher in Caco-2 respect to SW480 cell line $(P<0.05)$. Contrary to ferulic acid, the reduced methylated molecule, DHF, was less effective than DHC in SW480 cancer cells. Indeed, DHC showed higher anti-proliferative activity than caffeic acid. This, however, was not observed for DHF, which was less efficient than ferulic acid in inhibiting SW480 cell proliferation. $\mathrm{IC}_{50}$ values for DHC and DHF against Caco-2 cell proliferation were calculated revealing that DHF was significantly more effective than DHC $(71.7 \pm 1.1$ and $83.1 \pm 1.1 \mu \mathrm{mol} / \mathrm{L}$,

181 respectively; $P<0.05)$.

\subsection{Stability of hydroxycinnamic acid standards and colonic metabolites in cell-free media}

Identification of the standard compounds and metabolites in cell media was based on LC-ESIMS/MS analyses, and a summary of mass spectrometry data in negative ionization mode is presented in Table 2.

187 Results about the stability of individual hydroxycinnamic acids after $24 \mathrm{~h}$ incubation with DMEM 188 (Caco-2 medium) and L-15 (SW480 cell medium) cell-free media are given in Table 3. Some 189 hydroxycinnamic standards, such as $p$-coumaric, $o$-coumaric, ferulic and cinnamic acids, were very stable even after $24 \mathrm{~h}$ incubation in both the cell media. Whereas, caffeic acid was stable during 
191 incubation with L-15 but significantly degraded in DMEM after $24 \mathrm{~h}$ of incubation $(P<0.05)$.

192 However, the other tested compounds such as DHC, DHF and 5-CQA were significantly degraded 193 during incubation with both cell-free media $(P<0.05)$. A new peak with $m / z$ value of 300 appeared 194 after incubation of DHC in L-15 but not in DMEM (Figure S1). The fragmentation pattern 195 observed in the LC-MS/MS experiments (fragment ions at $m / z 213,181,135$ and 107) was coherent 196 with the formation of a DHC-cysteine adduct. ${ }^{21}$ The concentration of the DHC-cysteine adduct 197 (quantified as DHC equivalent) accounted for the $40.9 \%$ of the initial DHC dose, explaining the 198 loss of DHC in L-15.

199 Regarding 5-CQA, after $24 \mathrm{~h}$ of incubation in both cell media, two new peaks at $\mathrm{m} / \mathrm{z} 353$ were 200 observed (Figure S2). These new formed compounds showed the typical fragmentation pattern of 201 3-caffeoylquinic acid $\left(\mathrm{MS}^{2}\right.$ fragment ions at $\mathrm{m} / \mathrm{z} 191$ and 179) and 4-caffeoylquinic acid $\left(\mathrm{MS}^{2}\right.$ 202 fragment ions at $\mathrm{m} / \mathrm{z} 179,173,135$ and 191) suggesting that this compound underwent 203 isomerization during $24 \mathrm{~h}$ incubation. ${ }^{18}$ The sum of the percentage recovery of the three different 204 isomers of caffeoyl-quinic acid accounted for the $100 \%$ of the original standards in L-15 whereas in 205 DMEM the total recovery was $85.9 \%$ (Figure $\mathbf{2 A}$ and $\mathbf{B}$ ).

206 The production of $\mathrm{H}_{2} \mathrm{O}_{2}$ was measured after $24 \mathrm{~h}$ of incubation of hydroxycinnamic acids with cell207 free media at concentration of $200 \mu \mathrm{mol} / \mathrm{L}$. In DMEM caffeic acid, DHC and 5-CQA degradation 208 was accompanied to the generation of $\mathrm{H}_{2} \mathrm{O}_{2}$. The highest amounts of $\mathrm{H}_{2} \mathrm{O}_{2}$ were found in caffeic 209 acid and DHC (199.1 \pm 17.4 and 241.3 $\pm 12.2 \mu \mathrm{mol} / \mathrm{L}$, respectively) followed by 5-CQA (155.3 \pm $2106.3 \mu \mathrm{mol} / \mathrm{L}$ ). No evidence of $\mathrm{H}_{2} \mathrm{O}_{2}$ production was observed in the other hydroxycinnamic acids 211 incubated with DMEM. Indeed, no compounds led to the production of $\mathrm{H}_{2} \mathrm{O}_{2}$ during incubation in $212 \mathrm{~L}-15$. The $\mathrm{H}_{2} \mathrm{O}_{2}$ production was also tested after $24 \mathrm{~h}$ incubation of DHC in DMEM at $100 \mu \mathrm{mol} / \mathrm{L}$ 213 (corresponding to about the $\mathrm{IC}_{50}$ value against Caco-2 as reported above), resulting in a $\mathrm{H}_{2} \mathrm{O}_{2}$ 214 concentration of $173.7 \pm 16.0 \mu \mathrm{mol} / \mathrm{L}$. 
218 All the tested compounds underwent considerable biotransformations in Caco-2 and SW480 cancer cells and several newly-formed metabolites were identified (Table 4). In Caco-2, $o$-coumaric acid was extensively glucuronidated with the appearance of two isomers of coumaric acid-glucuronide showing a $[\mathrm{M}-\mathrm{H}]^{-}$deprotonated ion at $m / z, 339$, fragmenting to $m / z, 163$ (loss of glucuronide moiety) and with the characteristic fragmentation pattern of coumaric $(\mathrm{m} / \mathrm{z} 119)$ and glucuronic acids ( $m / z, 175$ and 113) (Table 2 and Figure S3). The glucuronide-derivative of $p$-coumaric acid was instead found only at trace levels (Table 4). Two additional metabolites were found in Caco-2 after incubation with $p$-coumaric acid: cinnamic acid (identified by comparison with its corresponding standard) and di-hydro-coumaric acid ( $\mathrm{m} / \mathrm{z}, 165$, fragmenting to $\mathrm{m} / \mathrm{z} 121$ corresponding to the loss of $\mathrm{CO}_{2}$ ). Metabolism by Caco-2 of ferulic acid resulted mainly in the formation of ferulic acid-glucuronide $(\mathrm{m} / \mathrm{z}, 369$, fragmenting to $\mathrm{m} / \mathrm{z}, 193$, corresponding to the loss of the glucuronide moiety, 175 and 113). Lower amounts of ferulic acid-sulphate $(\mathrm{m} / \mathrm{z}, 273$, fragmenting to $\mathrm{m} / \mathrm{z}, 193$ corresponding to the loss of sulphate group) and DHF (identified by comparison with its corresponding standard) were also found (Table 4). The most important metabolites found after incubation of caffeic acid and 5-CQA were (iso)ferulic acid (identified by comparison with its corresponding standard) and 5-feruloylquinic acid ( $\mathrm{m} / \mathrm{z} 367$, fragmenting to $\mathrm{m} / \mathrm{z}$ 179 and 135) while DHF was found only in trace amounts after incubation of DHC with Caco-2 cells (Table 4). Evidence of oxidation of the microbial metabolites DHC and DHF in caffeic and ferulic acids (identified by comparison with standard compounds) was observed after incubation with Caco-2 cells. Small amounts of DHF-sulphate $(\mathrm{m} / \mathrm{z} 2$ 275, fragmenting to $\mathrm{m} / \mathrm{z} 195$ corresponding to the loss of sulphate group) and DHF-glucuronide $(\mathrm{m} / \mathrm{z} 371$, fragmenting to $\mathrm{m} / \mathrm{z} 195$, corresponding to the loss of the glucuronide moiety, and 113) were found after incubation of DHF with Caco-2. 5-CQA underwent isomerization in 4- and 3-caffeoylquinic acids as observed also 
241 after incubation with cell-free medium (Table 4 and Figure 2A). The appearance of caffeic acid in

242 the cell medium after incubation of 5-CQA with Caco-2 was indicative of the presence of esterase

243 activity. Hydroxylation of cinnamic acid to coumaric acid (identified by comparison with standard

244 compounds) was the only metabolic pathway observed after incubation of cinnamic acid with Caco-

2452.

246 A slightly different metabolic profile was observed with SW480 since the major metabolites found

247 after incubation with $o$-coumaric, caffeic and ferulic acids as well as DHC and DHF were the

248 sulphate conjugates (Table 4). Caffeic acid-sulphate and DHC-sulphate were identified from the

249 respective parent ions at $m / z 259$ and 261 producing daughter ions at $m / z \quad 179$ and 181 (loss of

250 sulphate group), the un-conjugated forms, by $\mathrm{MS}^{2}$ analysis. Coumaric acid-sulphate $(\mathrm{m} / \mathrm{z} 243)$

251 yielded $\mathrm{MS}^{2}$ fragment ions at $m / z 163$ and 119 , corresponding to the loss of the sulphate moiety

252 generating coumaric acid and $\mathrm{CO}_{2}$ from the unconjugated molecule, respectively. Trace amounts of

253 coumaric acid were observed after incubation of caffeic acid with SW480. Instead, no sulphate

254 conjugates were found for $p$-coumaric acid, which was extensively reduced to di-hydro-coumaric

255 acid. The latter was also detected after incubation of $o$-coumaric acid with SW480 but only in trace

256 levels. As observed after incubation with cell-free medium, 5-CQA underwent isomerization with

257 the formation of the 3- and 4-acyl isomers (Table 4 and Figure 2B). Evidence of SW480 esterase

258 activity should be confirmed by the appearance of free hydroxycinnamic acids after incubation with

259 5-CQA. Moreover, cinnamic acid was particularly stable with only trace amounts of coumaric acid 260 detected in the supernatant after incubation with SW480, highlighting the hydroxylating ability of 261 these cells. 
The application of the solid phase extraction method on in vitro digested Celeste cherry cultivar and

265 dark chocolate allowed us to obtain fractions enriched in coumaroylquinic acids and

266 hydroxycinnamoyl aspartates, respectively.

267 Figure 3A shows the extracted ion chromatograms at $\mathrm{m} / \mathrm{z} 337$ (corresponding to the deprotonated coumaroylquinic acid molecules) after direct infusion in the mass spectrometer of the different

269 fractions obtained from the extraction procedure with in vitro digested Celeste cherry cultivar. As 270 shown, cherry ACN2 was the most enriched fraction in coumaroylquinic acids. The total ion 271 chromatogram of this fraction determined by direct infusion mass spectrometry revealed the presence of a prominent signal at $m / z 337$ and others minor signals at $m / z 353$ and 413 (Figure 3B). The LC-MS/MS experiments carried out on fraction ACN2 revealed the presence of seven resolved peaks (Figure 3C). Table 5 lists the compounds identified in the different observed peaks. The identification was based on previously reported paper. ${ }^{18}$ The amount of recovered 4coumaroylquinic and 5-coumaroylquinic acids (sum of the two isomers) were $72.3 \pm 0.9$ and $27.7 \pm$ $0.2 \mu \mathrm{mol} / \mathrm{L}$, respectively.

The direct infusion mass spectrometry of the different fractions obtained with solid phase extraction from in vitro digested dark chocolate revealed the presence of the typical $\mathrm{m} / \mathrm{z}$ values of

280 hydroxycinnamoyl aspartates $(\mathrm{m} / \mathrm{z}, 278,294$ and 308 for coumaroyl-aspartate, caffeoyl-aspartate and 281 feruloyl-aspartate, respectively) in both the chocolate ACN1 and ACN2 fractions (data not shown). 282 These fractions were further analyzed by liquid chromatography mass spectrometry (LC-MS/MS). 283 The extracted ion chromatograms of the $\mathrm{m} / \mathrm{z}$ values corresponding to the hydroxycinnamoyl 284 aspartates (Figure 4A-C) showed that fraction ACN2 contained higher amount of these compounds 285 respect to fraction ACN1. The LC-MS/MS experiments carried out on fraction ACN2 revealed the 286 presence of several peaks as detailed in the base peak chromatogram showed in Figure 4D.

287 Compounds identified in the observed peaks are reported in Table 5. The identification was based 288 on previously reported paper. ${ }^{22}$ The amount of recovered coumaroyl-aspartate, caffeoyl-aspartate 
and feruloyl-aspartate (sum of the two isomers) were 448.2 $\pm 73.5,110.3 \pm 16.6$ and $66.1 \pm 9.9$ $\mu \mathrm{mol} / \mathrm{L}$, respectively.

\subsection{Anti-proliferative activity, stability in cell-free media and cell metabolism of coumaroylquinic} acids and hydroxycinnamoyl aspartates enriched fractions

Coumaroylquinic acids and hydroxycinnamoyl aspartates enriched fractions were tested for their anti-proliferative activity after two-fold dilution in cell media. Both the fractions showed notably anti-proliferative activity against SW480 cells whereas only the hydroxycinnamoyl aspartates enriched fraction was able to slightly inhibit Caco-2 cell proliferation (Table 1). Table 3 shows data about the stability of coumaroylquinic acids and hydroxycinnamoyl aspartates after $24 \mathrm{~h}$ incubation with DMEM (Caco-2 medium) and L-15 (SW480 cell medium) cell-free media. Results showed that coumaroylquinic acids were subject to isomerization in both the cell media (Figure 2C and D). After $24 \mathrm{~h}$ incubation in DMEM, the amount of 4-coumaroylquinic acid decreased by about $43 \%$, whereas the amount of 5-coumaroylquinic acid increased slightly but significantly $(P<0.05)$. A new signal at $m / z 337$ was recorded after incubation in DMEM with MS $^{2}$ product ions at 163,119 and 191 characteristic of the 3-acyl isomer of coumaroylquinic acid. ${ }^{18}$ The sum of the percentage recovery of the three different isomers accounted for about $83 \%$ of the original amount. In L-15, the amount of both the 4- and 5-acyl isomers decreased with the concurrent formation of the 3-acyl isomer. Incubation of coumaroylquinic acids enriched fraction with Caco-2 resulted in the formation of some metabolites (Table 4). Hydrolysis of the quinic acid-derivatives by cell esterases led to the formation of the free coumaric acid. Both coumaroylquinic and coumaric acids were also 310 detected in the glucuronidated forms. Coumaroylquinic acid-glucuronide showed a precursor ion at $311 \mathrm{~m} / \mathrm{z}, 513$ and fragmented at $\mathrm{m} / z 337$ (loss of the glucuronide moiety). The appearance of di-hydro312 coumaric acid may be a consequence of the reduction of coumaric acid released from the quinic 
313 acid-derivative. Isomerization to 3-coumaroyl-quinic acid was also observed as reported after 314 incubation with cell-free medium (Table 3 and Figure 2C).

315 The total recovery considering the three isomers was $92.4 \%$. Coumaroyl-aspartate was quite stable 316 during incubation with both the cell-free media whereas the feruloyl- and caffeoyl-derivatives were 317 partially degraded (Figure $\mathbf{2 E}$ and $\mathbf{F}$ ). The only metabolites found after incubation of 318 hydroxycinnamoyl aspartates enriched fraction with Caco-2 cells were the corresponding free 319 hydroxycinnamic acids. However, feruloyl-aspartate was detected in higher amounts after 320 incubation with Caco-2 respect to the incubation in cell-free medium suggesting the possible 321 methylation of the caffeoyl derivative (Table 4 and Figure 2E). Finally, the only metabolite 322 detected after incubation of the coumaroyl-quinic acid and hydroxycinnamoyl aspartates enriched 323 fractions with SW480 cells were coumaric and caffeic acids, respectively.

\section{Discussion}

Degradation of phenolic compounds during incubation in cell media and their putative cellular metabolism may represent a limitation in their biological activity such as the anti-proliferative activity.

In this study, we found that the stability of hydroxycinnamic acids in Caco-2 cell medium (DMEM; $\mathrm{pH}$ 7.4) was strongly correlated with structural motifs of the molecules. The presence of a catecholtype structure in the aromatic ring weakened the stability of hydroxycinnamic acids in DMEM. For example, caffeic acid bearing a catechol-type structure was clearly less stable than the monohydroxylate coumaric acid or ferulic acid where one of the two hydroxyl groups is methylated. Similarly, DHC was less stable than DHF in Caco- 2 cell medium. Hydrogenation of the $\mathrm{C}_{7}=\mathrm{C}_{8}$ double bond of hydroxycinnamic acids to corresponding di-hydro-hydroxycinnamic acids also decreased the stability of the compounds. Phenolic compounds with a catechol-type structure are easily oxidized at alkaline or slightly alkaline $\mathrm{pH}$ values in presence of $\mathrm{O}_{2}$ via the semiquinone 
338 intermediate formation. ${ }^{15,23}$ The oxidative degradation of these compounds generate $\mathrm{O}_{2} \bullet^{-}$which 339 enhance the rate of autoxidation resulting in the formation of $\mathrm{H}_{2} \mathrm{O}_{2} \cdot{ }^{23}$ In agreement, we found that 340 the decrease of caffeic acid and DHC in DMEM resulted in the production of $\mathrm{H}_{2} \mathrm{O}_{2}$ suggesting that 341 the oxidative degradation pathway was the main one of these compounds in DMEM. The stability 342 of 5-CQA in DMEM was similar to that of caffeic acid; however, the degradation pathways were 343 slightly different. In addition to the oxidative degradation, the positional isomers 3-CQA and 4344 CQA were also produced during incubation. This finding agrees with the results obtained in 345 previous studies. ${ }^{13,24}$

346 The stability profile of the hydroxycinnamic acids in the SW480 cell medium (L-15; pH 7.4) was 347 quite different respect to those observed after incubation in DMEM. In fact, caffeic acid was stable 348 during incubation in L-15 suggesting that the oxidative degradation did not occur. Indeed, no $\mathrm{H}_{2} \mathrm{O}_{2}$ 349 production was detected in L-15. Surprisingly, DHC was partially degraded after $24 \mathrm{~h}$ of incubation 350 in L-15 medium. However, this was not a consequence of the oxidative degradation pathway (no 351 formation of $\mathrm{H}_{2} \mathrm{O}_{2}$ was observed) but was related to the formation of a DHC-cysteine adduct. This 352 adduct was not formed in DMEM since cysteine was absent from the medium.

353 DHF was partially degraded in both the media thorough a not yet identified pathway that did not 354 involve oxidative degradation, as suggested by the absence of $\mathrm{H}_{2} \mathrm{O}_{2}$ in the cell media.

355 Our data provide evidence that Caco-2 and SW480 cells are able to metabolize hydroxycinnamic 356 acids by means of phase I and phase II enzymes. Figures 5 and $\mathbf{6}$ summarize the metabolic 357 reactions detected in Caco-2 and SW480 cell lines, showing pathways for phase I de-esterification 358 and hydroxylation and phase II glucuronidation, sulphation, and $O$-methylation of the various 359 hydroxycinnamic acids substrates used in this study.

360 In both the cell lines, small amounts of caffeoylquinic and coumaroylquinic acids were hydrolyzed 361 resulting in the appearance of free hydroxycinnamic acids. Kern and colleagues reported the 362 presence of both intracellular and extracellular esterases in Caco-2. ${ }^{25}$ Farrel et al. ${ }^{26}$ suggested that 
serine hydrolases might be responsible for the cinnamoyl esterase activity of cultured gastric cells since these carboxylesterases share similar structural homology and mechanism of hydrolysis with cinnamoyl esterases. This class of enzymes was detected in Caco-2 cells, as well as in the intestinal mucosa. ${ }^{26-28}$ Esterases activity was more heightened in Caco-2 cells respect to SW480. Williamson et al. ${ }^{28}$ evidenced that Caco-2 esterases were active against 3-O-caffeoylquinic acid but not versus 5-O-caffeoylquinic and feruloylquinic acids. Here we gave evidence, for the first time, of the activity of cell esterases against coumaroylquinic acids. We also reported for the first time the ability of SW480 and, especially, Caco-2 cells to release simple acids (such as caffeic, coumaric and ferulic acids) from hydroxycinnamoyl-aspartates. In this sense, a hydrolysis of hydroxycinnamoyl-aspartates catalyzed by membrane bound carboxypeptidases may be hypothesized.

Our data showed that other phase I reactions might be involved in the metabolism of hydroxycinnamic acids. Hydroxylation by cytochrome P450 of cinnamic acid resulted in the formation of coumaric acid. Moreover, de-hydroxylation by phase I reductases brought about the formation of cinnamic and coumaric acids from coumaric and caffeic acids, respectively. Whereas, phase II metabolism was found to be cell line- and compound-dependent and varied notably between the two cell lines and the compounds considered. Major pathways in Caco-2 cells were glucuronidation and methylation whereas in SW480 sulphation was the predominant one. Caco-2 UDP-glucuronosyltransferase activity was strongly depended on the type of substrate. Glucuronidation was a major pathway in ferulic acid metabolism whereas caffeic acid was only slightly glucuronidated. This result suggested that the presence of the catechol group hinder the action of the UDP-glucuronosyltransferase. This observation was also supported by the fact that $o$ coumaric acid was a good substrate for UDP-glucuronosyltransferase. The activity of UDPglucuronosyltransferase was also dependent on the position of the $\mathrm{OH}$ group in the aromatic ring as evidenced from the missing identification of glucuronidated metabolites of $p$-coumaric acid. 
Methylation by catechol- $O$-methyl transferase was the preferential pathway for caffeic acid metabolism (both when present as free acid and when conjugate with quinic acid or aspartate), while ferulic and coumaric acids, lacking the catechol structure, could not be methylated by catechol-O-methyltransferase. Reduction of ferulic acid to DHF as well as oxidation of DHC to caffeic acid and DHF to ferulic acid were observed, as already reported by Poquet et al. ${ }^{29}$ Previous studies with Caco-2 found di-hydro-ferulic acid and ferulic acid-sulphate as the main metabolite originated from ferulic acid whereas the glucuronidated forms were detected only at trace levels. ${ }^{25,30,31}$ Farrel et al. ${ }^{31}$ and Monente et al. ${ }^{30}$ also detected caffeic acid-sulphate after incubation of caffeic acid with Caco-2. Differences between our study and previous works could be related to the hydroxycinnamic acids incubation with differentiated Caco-2. On the other hand, incubation for $23 \mathrm{~h}$ of ferulic and caffeic acids with non-differentiated Caco-2 (as in our study) resulted in the appearance of the glucuronidated derivatives without any evidence of sulphation. ${ }^{32}$ 400 Altogether, these results pointed out a different metabolism between differentiated and non401 differentiated Caco-2 cells. No previous studies were available in literature concerning the metabolism of hydroxycinnamic acids with SW480.

403 The instability of some hydroxycinnamic acids in Caco-2 cell media may partially explain the 404 observed results regarding the anti-proliferative activity of hydroxycinnamic acids. During 405 incubation with Caco-2, caffeic acid was drastically degraded by the oxidative pathway hindering 406 the detection of any biological activities. Furthermore, caffeic acid was definitely more stable in L40715 than DMEM and was able to reduce SW480 cells proliferation. In addition, 5-CQA was partially 408 degraded in both the cell media and was devoid of any activity.

409 The correlation between the observed effects and the stability in the cell media is not always 410 evident. This is the case of DHC, which was particularly unstable in DMEM resulting in the 411 formation of $\mathrm{H}_{2} \mathrm{O}_{2}$. Despite degradation, DHC was able to reduce Caco-2 cell proliferation in a 412 concentration-dependent manner. This effect could be related to the production of $\mathrm{H}_{2} \mathrm{O}_{2}$. However, 
413 caffeic acid degradation resulted in $\mathrm{H}_{2} \mathrm{O}_{2}$ production similar to that observed when DHC was

414 incubated at $100 \mu \mathrm{mol} / \mathrm{L}$ (corresponding at about the $\mathrm{IC}_{50}$ value against Caco-2) without anti-

415 proliferative activity. These observations suggest that $\mathrm{H}_{2} \mathrm{O}_{2}$ did not have a key role in the anti-

416 proliferative action of DHC. Similarly, DHF was quite unstable in both the media but was able to

417 exert anti-proliferative effect.

418 Phase II enzymes in Caco-2 cells extensively metabolized some hydroxycinnamic acids, such as 419 coumaric, ferulic and coumaroyl-quinic acids. Previous studies demonstrated that phase II 420 metabolites of phenolic compounds presented reduced biological activities respect to the parent 421 compounds. ${ }^{33,34}$ González-Sarrías and co-worker demonstrated that glucuronidation of urolithins 422 during incubation with HT29 cells limits their anti-proliferative activity. ${ }^{33}$ Similarly, 423 glucuronidation of hesperetin by Raw264.7 cells reduced its anti-inflammatory activity. ${ }^{35}$ In this 424 study, we found that SW480 cells displayed lower metabolic activity and the majority of the 425 hydroxycinnamic acids showed appreciable anti-proliferative activity. Ferulic acid was clearly 426 stable in both the cell media but active only against SW480 proliferation. During incubation with 427 Caco-2 ferulic acid was extensively glucuronidated and, to a lesser extent, sulphated. The Caco-2 428 metabolism of ferulic acid may have hampered their anti-proliferative activity against this cell line.

429 Some of the tested standard compounds and metabolites were recovered in significantly lower 430 amount after incubation with cells (Table 4) respect to the amount observed after incubation with 431 cell-free media (Table 3) such as p-coumaric acid, caffeic acid and DHF in Caco-2 and caffeic acid, $432 \quad o$-coumaric acid, ferulic acid and 5-CQA in SW480. These compounds could be metabolized in un433 identified compounds or transported inside the cells. Some studies suggest that hydroxycinnamic 434 acids can be transported in Caco-2 cells. For example, Konishi and co-worker reported that $p$ 435 coumaric and caffeic acids but not 5-CQA were efficiently transported across Caco-2 membrane 436 via the monocarboxylic acid transporter (MCT). ${ }^{36}$ Moreover, Monente et al. found that the 437 transepithelial transport of DHF in Caco-2 cells was more pronounced than that of DHC. ${ }^{30}$ No 
studies about the possible transport of phenolic compounds across SW480 are present in literature.

439 However, these colon cancer cells express high level of MCT. ${ }^{37}$

440 It is useful mentioning that the observed different susceptibility of the two studied cancer cell lines

441 could reflect their different gene expressions, differentiation stages, proliferative rates, nevertheless

442 their distinct capacity to metabolize and accumulate hydroxycinnamic acids.

443 Despite their stability in the upper gastro-intestinal tract, hydroxycinnamic acids are thoroughly

444 modified in the colon by the action of colonic microbiota. Ludwig and colleagues identified a total

445 of 11 metabolites after in vitro colonic fermentation by human microbiota of coffee caffeoylquinic

446 and feruloylquinic acids. ${ }^{38}$ However, basing on quantitative data, they observed that major

447 degradation pathways led to the accumulation of DHC and DHF. ${ }^{38}$ Further in vivo studies have

448 confirmed free and sulphated DHC and DHF as main metabolites in plasma and urine after

449 ingestion of coffee. ${ }^{39,40}$ DHC and DHF have also been identified after in vitro colonic fermentation

450 of blueberries, oat and wheat bran, orange and apple juices as well as black and green tea. ${ }^{41}$

451 Therefore, it is important to investigate the potential anti-proliferative effect of hydroxycinnamic

452 acid colonic metabolites in colon adenocarcinoma cell systems. ${ }^{42}$ The results with the reduced

453 microbial metabolites, DHC and DHF, showed that they were more effective than the parent

454 compounds in inhibiting Caco-2 proliferation. DHC was also more active than caffeic acid against

455 SW480 whereas ferulic acid was more effective than DHF in inhibiting SW480 proliferation.

456 In addition to standard hydroxycinnamic acids and colonic metabolites, we also tested two different

457 extracts obtained from in vitro digested cherry and dark chocolate with the aim to increase our

458 previous findings and identify the possible compounds involved in the already reported anti-

459 proliferative activity. ${ }^{13,14}$ The two extracts were enriched in coumaroylquinic acids (from digested

460 cherry) and hydroxycinnamoyl aspartates (from digested dark chocolate). Similarly to what was

461 observed for in vitro digested cherry, the coumaroylquinic acids enriched extract was effective

462 against SW480 but not on Caco-2 cell proliferation. These results pointed out that this fraction 
463

contained the causative compounds of the anti-proliferative activity of in vitro digested cherry. ${ }^{13}$

This extract was enriched in coumaroylquinic acids but also contained other compounds such as 3and 4-caffeoylquinic acids and roseoside. In this study, we demonstrated that caffeoylquinic acids were not effective against SW480 cells proliferation. Concerning roseoside, no studies about its effect on colon cancer Caco-2 and SW480 cells were found in literature. Differently, the hydroxycinnamoyl aspartates extract was able to inhibit the proliferation of both the colon cancer cell lines but was three-times more effective against SW480. These results fitted with the data obtained with in vitro digested dark chocolate and suggested that this fraction contained the active compounds. ${ }^{14}$ Besides hydroxycinnamoyl aspartates, the extract also contained (epi)catechin sulphate and 12-hydroxy jasmonic acid sulphate. Ramos et al. reported that $24 \mathrm{~h}$ treatment of Caco2 and SW480 with catechin, epicatechin or procyanidin B2 did not affect cell growth. ${ }^{43}$ No studies about the effect of 12-hydroxy jasmonic acid sulphate on colon cancer Caco-2 and SW480 cells or against others cancer cell lines were found in literature. However, methyl jasmonic acid was found to be able to inhibit in vitro cancer cell proliferation and to induce cell death in several cancer cell lines, including colon cancer HT29. ${ }^{44}$

These results indicated that some hydroxycinnamic acids at a concentration close to those which they can achieve in the gastro-intestinal tract after the consumption of hydroxycinnamic acid-rich foods and beverages, may exert anti-proliferative activity. In particular, the remarkable effect of dihydro-caffeic and di-hydro-ferulic acids against cell proliferation is of paramount importance since these compounds are the main metabolites detectable at colonic level after the consumption of hydroxycinnamates-rich foods. This study suggests that these metabolites could be the real active molecules involved in the reported biological effects of hydroxycinnamic acid-rich foods, especially those effects related to gastrointestinal pathologies such as colon cancer.

Our results highlighted that the drastic biotransformations of hydroxycinnamic acids occurring in cell cultures should be carefully taken into account in order to fully understand the real compounds 
488 exerting the observed bioactivities. Some compounds were drastically degraded in culture medium 489 whereas some other compounds were extensively metabolized in phase II metabolites, which could 490 have resulted in a reduction of their anti-proliferative activity. This integrated approach may 491 therefore be relevant to understand the molecules and mechanisms responsible for the biological 492 effects of phenolic metabolites.

493 Finally, hydroxycinnamic acids and especially their colonic metabolites di-hydro-caffeic and di494 hydro-ferulic acids might have interesting anti-proliferative potential in colon cancer prevention, 495 warranting further studies to confirm this relationship as well as the possible mechanisms of action. 


\section{Acknowledgment}

The authors acknowledge the Fondazione Cassa di Risparmio di Modena for funding the HPLCESI-IT system at the Centro Interdipartimentale Grandi Strumenti (CIGS). 


\section{References}

1. Del Rio, D.; Rodriguez-Mateos, A.; Spencer, J. P. E.; Tognolini, M.; Borges, G.; Crozier, A. Dietary (Poly)phenolics in human health: structures, bioavailability, and evidence of protective effects against chronic diseases. Antioxid. Redox Signal. 2013, 18, 1818-1892.

2. Chen, H.; Liu, R. H. Potential mechanisms of action of dietary phytochemicals for cancer prevention by targeting cellular signalling transduction pathways. J. Agric. Food Chem. 2018, 66, 3260-3276.

3. Clifford, M. N.; Jaganath, I. B.; Ludwig, I. A.; Crozier, A. Chlorogenic acids and the acylquinic acids: discovery, biosynthesis, bioavailability and bioactivity. Nat. Prod. Rep. 2017, 34, 1391-1421.

4. Rice-Evans, C. A.; Miller, N. J.; Paganga, G. Structure- antioxidant activity relationships of flavonoids and phenolic acids. Free Rad. Biol. Med. 1996, 20, 933-956.

5. Di Mattia, C. D..; Sacchetti, G.; Mastrocola, D.; Serafini, M. From cocoa to chocolate: The impact of processing on in vitro antioxidant activity and the effects of chocolate on antioxidant markers in vivo. Front. Immunol. 2017, 8, 1207.

6. Halliwell, B.; Rafter, J.; Jenner, A. Health promotion by flavonoids, tocopherols, tocotrienols, and other phenols: direct or indirect effects? Antioxidant or not? Am. J. Clin. Nutr. 2005, 81, 268S-276S.

7. Vitaglione, P.; Fogliano, V.; Pellegrini, N. Coffee, colon function and colorectal cancer. Food Funct. 2012, 3, 916-922.

8. Jedrychowski, W.; Maugeri, U. An apple a day may hold colorectal cancer at bay: recent evidence from a case-control study. Rev. Environ. Health 2009, 24, 59-74.

9. Guercio, B. J.; Sato, K.; Niedzwiecki, D.; Ye, X.; Saltz, L. B.; Mayer, R. J.; Mowat, R. B.; Whittom, R.; Hantel, A.; Benson, A.; Atienza, D.; Messino, M.; Kindler, H.; Venook, A.; Hu, F. B.; Ogino, S.; Wu, K.; Willett, W. C.; Giovannucci, E. L.; Meyerhardt, J. A.; Fuchs, 
C. S. Coffee intake, recurrence, and mortality in stage III colon cancer: results from CALGB 89803 (Alliance). J. Clin. Oncol. 2015, 33, 3598-3607.

10. Schmit, S. L.; Rennert, H. S.; Rennert, G.; Gruber, S. B. Coffee consumption and the risk of colorectal cancer. Cancer Epidemiol. Biomark. Prev. 2016, 25, 634-639.

11. Kang, S. Y.; Seeram, N. P.; Nair, M. G.; Bourquin, L. D. Tart cherry anthocyanins inhibit tumor development in ApcMin mice and reduce proliferation of human colon cancer cells. Cancer Lett. 2003, 194, 13-19.

12. Hong, M. Y.; Nulton, E.; Shelechi, M.; Hernández, L. M.; Nemposeck, T. Effects of dark chocolate on azoxymethane-induced colonic aberrant crypt foci. Nutr. Cancer 2013, 65, 677 $-685$.

13. Martini, S.; Conte, A.; Tagliazucchi, D. Bioactivity and cell metabolism of in vitro digested sweet cherry (Prunus avium) phenolic compounds. Int. J. Food Sci. Nutr. 2019, 70, 335348.

14. Martini, S.; Conte, A.; Tagliazucchi, D. Bioaccessibility, bioactivity and cell metabolism of dark chocolate phenolic compounds after in vitro gastro-intestinal digestion. J. Funct. Foods 2018, 49, 424-436.

15. Xiao, J.; Högger, P. Stability of dietary polyphenols under the cell culture conditions: avoiding erroneous conclusions. J. Agric. Food Chem. 2015, 63, 1547-1557.

16. Aragonès, G.; Danesi, F.; Del Rio, D.; Mena, P. The importance of studying cell metabolism when testing the bioactivity of phenolic compounds. Trends Food Sci. Technol. 2017, 69, 230-242.

17. Tagliazucchi, D.; Verzelloni, E.; Conte, A. Antioxidant properties of traditional balsamic vinegar and boiled must model systems. Eur. Food Res. Technol. 2008, 227, 835-843.

18. Martini, S.; Conte, A.; Tagliazucchi, D. Phenolic compounds profile and antioxidant properties of six sweet cherry (Prunus avium) cultivars. Food Res. Int. 2017, 97, 15-26. 
19. Sala, R.; Mena, P.; Savi, M.; Brighenti, F.; Crozier, A.; Miragoli, M.; Stilli, D.; Del Rio, D. Urolithins at physiological concentrations affect the levels of pro-inflammatory cytokines and growth factor in cultured cardiac cells in hyperglucidic conditions. J. Funct. Foods $\mathbf{2 0 1 5}, 15,97-105$.

20. Martini, S.; Cavalchi, M.; Conte, A.; Tagliazucchi, D. The paradoxical effect of extra-virgin olive oil on oxidative phenomena during in vitro co-digestion with meat. Food Res. Int. 2018, 109, 82-90.

21. Levsen, K.; Schiebel, H. M.; Behnke, B.; Dötzer, R.; Dreher, W.; Elend, M.; Thiele, H. Structure elucidation of phase II metabolites by tandem mass spectrometry: an overview. $J$. Chromatogr. A 2005, 1067, 55-72.

22. Martini, S.; Conte, A.; Tagliazucchi, D. Comprehensive evaluation of phenolic profile in dark chocolate and dark chocolate enriched with Sakura green tea leaves or turmeric powder. Food Res. Int. 2018, 112, 1-16.

23. Mochizuki, M.; Yamazaki, S.; Kano, K.; Ikeda, T. Kinetic analysis and mechanistic aspects of autoxidation of catechins. Biochim. Biophys. Acta 2002, 1569, 35-44.

24. Xie, C.; Yu, K.; Zhong, D.; Yuan, T.; Ye, F.; Jarrell, J. A.; Millar, A.; Chen, X. Investigation of isomeric transformations of chlorogenic acid in buffers and biological matrixes by ultraperformance liquid chromatography coupled with hybrid quadruple/ion mobility/orthogonal acceleration time-of-flight mass spectrometry. J. Agric. Food Chem. 2011, 59, $11078-11087$.

25. Kern, S. M.; Bennet, R. M.; Needs, P. W.; Mellon, F. A.; Kroon, P. A.; Garcia-Canesa, M. T. Characterization of metabolites of hydroxycinnamates in the in vitro model of human small intestinal epithelium Caco-2 cells. J. Agric. Food Chem. 2003, 51, 7884 -7891. 
26. Farrell, T. L.; Dew, T. P.; Poquet, L.; Hanson, P.; Williamson, G. Absorption and metabolism of chlorogenic acids in cultured gastric epithelial monolayers. Drug Metab. Dispos. 2011, 39, 2338-2346.

27. Andreasen, M. F.; Kroon, P. A.; Williamson, G.; Garcia-Canesa, M. T. Esterase activity able to hydrolyze dietary antioxidant hydroxycinnamates is distributed along the intestine of mammals. J. Agric. Food Chem. 2001, 49, 5679 -5684.

28. da Encarnação, J. A.; Farrell, T. L.; Ryder, A.; Kraut, N. U.; Williamson, G. In vitro enzymic hydrolysis of chlorogenic acids in coffee. Mol. Nutr. Food Res. 2015, 231-239.

29. Poquet, L.; Clifford, M. N.; Williamson, G. Investigation of the metabolic fate of dihydrocaffeic acid. Biochem. Pharmacol. 2008, 75, 1218-1229.

30. Monente, C.; Ludwig, I. A.; Stalmach, A.; de Peña, M. P.; Cid, C.; Crozier, A. In vitro studies on the stability in the proximal gastrointestinal tract and bioaccessibility in Caco-2 cells of chlorogenic acids from spent coffee grounds. Int. J. Food Sci. Nutr. 2015, 66, 657664.

31. Farrel, T.; Poquet, L.; Dionisi, F.; Barron, D.; Williamson, G. Characterization of hydroxycinnamic acid glucuronide and sulfate conjugates by HPLC-DAD-MS2: Enhancing chromatographic quantification and application in Caco-2 cell metabolism. J. Pharm. Biomed. Anal. 2011, 55, 1245-1254.

32. Achour, M.; Saguem, S.; Sarriá, B.; Bravo, L.; Mateos, R. Bioavailability and metabolism of rosemary infusion polyphenols using Caco-2 and HepG2 cell model systems. J. Sci. Food Agric. 2018, 98, 3741-3751.

33. González-Sarrías, A.; Giménez-Bastida, J. A.; Núñez-Sánchez, M. Á.; Larrosa, M.; GarcíaConesa, M. T.; Tomás-Barberán, F. A.; Espin, J. C. Phase-II metabolism limits the antiproliferative activity of urolithins in human colon cancer cells. Eur. J. Nutr. 2014, 53, $583-864$. 
34. Wu, Q.; Kroon, P. A.; Shao, H.; Needs, P. W.; Yang, X. Differential effect of quercetin and two of its derivative, isorhamnetin and isorhamnetin-3-glucuronide, in inhibiting the proliferation of human breast-cancer MCF-7 cells. J. Agric. Food Chem. 2018, 66, 71817189.

35. Ma, Y.; He, Y.; Yin, T.; Chen, H.; Gao, S.; Hu, M. Metabolism of phenolic compounds in LPS-stimulated Raw264.7 cells can impact their anti-inflammatory efficacy: Indication of hesperetin. J. Agric. Food Chem. 2018, 66, 6042-6052.

36. Konishi, Y; Kobayashi, S. Transepithelial transport of cholorogenic acid, caffeic acid, and their colonic metabolites in intestinal Caco-2 cell monolayers. J. Agric. Food Chem. 2004, $52,2518-2526$.

37. Konishi, Y; Kobayashi, S.; Shimizu, M. Transepithelial transport of $p$-coumaric acid and gallic acid in Caco-2 cell monolayers. Biosci. Biotechnol. Biochem. 2003, 67, 2317 -2324.

38. Ludwig, I. A.; de Pena, M. P.; Cid, C.; Crozier, A. Catabolism of coffee chlorogenic acids by human colonic microbiota. BioFactors 2013, 39, 623-632.

39. Stalmach, A.; Mullen, W.; Barron, D.; Uchida, K.; Yokota, T.; Cavin, C.; Steiling, H.; Williamson, G.; Crozier, A. Metabolite profiling of hydroxycinnamate derivatives in plasma and urine after the ingestion of coffee by humans: identification of biomarkers of coffee consumption. Drug Metab. Dispos. 2009, 37, 1749-1758.

40. Stalmach, A.; Steiling, H.; Williamson, G.; Crozier, A. Bioavailability of chlorogenic acids following acute ingestion of coffee by humans with an ileostomy. Arch. Biochem. Biophys. 2010, 51, 98-105.

41. Dall'Asta, M.; Calani, L.; Tedeschi, M.; Jechiu, L.; Brighenti, F.; Del Rio, D. Identification of microbial metabolites derived from in vitro fecal fermentation of different polyphenolic food sources. Nutrition 2012, 28, 197-203. 
42. Mena, P.; Del Rio, D. Gold standards for realistic (poly)phenol research. J. Agric. Food Chem. 2018, 66, 8221-8223.

43. Ramos, S.; Rodríguez-Ramiro, I.; Martín, M. A.; Goya, L.; Bravo, L. Dietary flavanols exert different effects on antioxidant defenses and apoptosis/proliferation in Caco-2 and SW480 colon cancer cells. Toxicol. in Vitro 2011, 25, 1771 -1781.

44. Cesari, I. M.; Carvalho, E.; Rodrigues, M. F.; dos Santos Mendonça, B.; Amôedo, N. D.; Rumjanek, F. D. Methyl jasmonate: putative mechanisms of action on cancer cells cycle, metabolism, and apoptosis. Int. J. Cell Biol. 2014, 572097. 


\section{Figure captions}

Figure 1. Structure of hydroxycinnamic acids used in this study. $\mathrm{R} 1=\mathrm{OH}, \mathrm{R} 2=\mathrm{H}$ : $o$-coumaric acid. $\mathrm{R} 1=\mathrm{H}, \mathrm{R} 2=\mathrm{OH}$ : $p$-coumaric acid.

Figure 2. Recovery and isomerization of hydroxycinnamoyl-quinic acids and hydroxycinnamoyl aspartates. (A, C, E) Caco-2; (B, D, F) SW480. Black columns represent the percentage of the different isomers at the beginning of incubation (time 0 ). Light grey columns represent the percentage of the different isomers after $24 \mathrm{~h}$ of incubation in cell-free media. Dark grey columns represent the percentage of the different isomers after $24 \mathrm{~h}$ of incubation with cells. CQA: caffeoylquinic acid; CoQA: coumaroylquinic acid. Values in the same graph with different lowercase letter are significantly different $(P<0.05)$. Coumaroylquinic acids enriched fraction was obtained from in vitro digested cherry as reported in materials and methods section.

Hydroxycinnamoyl aspartates enriched fraction was obtained from in vitro digested dark chocolate as reported in materials and methods section.

Figure 3. Preparation of coumaroylquinic acids enriched fraction from in vitro digested cherry. (A) Extracted ion chromatogram at $\mathrm{m} / z 337$ from direct infusion of ACN fractions obtained from solid phase extraction of in vitro digested Celeste cherry cultivar. Dashed line represents ACN1 fraction. Solid line represents ACN2 fraction. Dotted line represents ACN3 fraction. Light grey solid line represents ACN4 fraction. Grey solid line represents methanolic fraction. (B) Total ion chromatogram obtained from direct infusion of fraction ACN2. (C) Base peak chromatogram of fraction ACN2.

\section{Figure 4. Preparation of hydroxycinnamoyl aspartates enriched fraction from in vitro}

digested dark chocolate. Extracted ion chromatograms at $\mathrm{m} / z 278$ (A), 294 (B) and 308 (C) from fraction ACN1 (solid black line) and ACN2 (solid grey line). (D) Base peak chromatogram of fraction ACN2. 
Figure 5. Proposed pathways for hydroxycinnamic acids metabolism after incubation with

Caco-2 cell line. COMT: catechol- $O$-methyl transferase; CPase: carboxypeptidase; EST: esterase;

RA: reduction; OX: oxidation; DHY: de-hydroxylation; HYD: hydroxylation; SULT:

sulfotransferase; UDP-GT: UDP-glucuronosyltransferase. Bold arrows indicate major routes.

Percentages indicate the extent of biotransformation.

Figure 6. Proposed pathways for hydroxycinnamic acids metabolism after incubation with

SW480 cell line. CPase: carboxypeptidase; EST: esterase; OX: oxidation; DHY: de-hydroxylation;

HYD: hydroxylation; SULT: sulfotransferase. Bold arrows indicate major routes. Percentages indicate the extent of biotransformation. 
Table 1. Effect of hydroxycinnamic acids and coumaroyl-quinic acids and hydroxycinnamoylaspartates-enriched fractions on the proliferation of colon adenocarcinoma human cell lines.

\begin{tabular}{|c|c|c|}
\hline Compound & $\begin{array}{c}\text { Caco-2 } \\
\% \text { inhibition }\end{array}$ & $\begin{array}{c}\text { SW } 480 \\
\% \text { inhibition }\end{array}$ \\
\hline \multicolumn{3}{|l|}{ Standards } \\
\hline Cinnamic acid & n.a. & n.a. \\
\hline$p$-Coumaric acid & n.a. & n.a. \\
\hline$o$-Coumaric acid & n.a. & $7.23 \pm 3.86^{\mathrm{e}}$ \\
\hline Caffeic acid & n.a. & $40.8 \pm 1.63^{c}$ \\
\hline Ferulic acid & n.a. & $59.9 \pm 1.29^{\mathrm{e}}$ \\
\hline 5-Caffeoylquinic acid & n.a. & n.a. \\
\hline Di-hydro-caffeic acid & $101 \pm 1.70^{\mathrm{a}}$ & $46.8 \pm 1.05^{b}$ \\
\hline Di-hydro-ferulic acid & $100 \pm 2.11^{\mathrm{a}}$ & $37.3 \pm 1.21^{\mathrm{cd}}$ \\
\hline \multicolumn{3}{|l|}{ Extracts } \\
\hline $\begin{array}{l}\text { Coumaroylquinic acids- } \\
\text { enriched fraction }\end{array}$ & n.a. & $41.4 \pm 3.31^{\mathrm{bc}}$ \\
\hline $\begin{array}{l}\text { Hydroxycinnamoyl } \\
\text { aspartates enriched fraction }\end{array}$ & $10.7 \pm 1.92^{\mathrm{e}}$ & $34.2 \pm 1.55^{\mathrm{d}}$ \\
\hline
\end{tabular}

Hydroxycinnamic acids were tested at $200 \mu \mathrm{mol} / \mathrm{L}$. Coumaroylquinic acids and hydroxycinnamoyl aspartates enriched fractions were tested after two-fold dilution in cell media. Coumaroylquinic acids final concentration in the cell media were 36.2 and $13.9 \mu \mathrm{mol} / \mathrm{L}$ for 4-coumaroyl-quinic and 5-coumaroyl-quinic acids, respectively. Hydroxycinnamoylaspartates concentration in the cell media were $224,55.2$ and $33.1 \mu \mathrm{mol} / \mathrm{L}$ for coumaroyl-aspartate, caffeoyl-aspartate and feruloyl-aspartate, respectively.

n.a. means no activity

Values with different uppercase letters are significantly different $(P<0.05)$. 
Table 2. Mass spectral characteristics of hydroxycinnamic acid standards and their metabolites identified in this study

\begin{tabular}{|c|c|c|}
\hline Compound & $\begin{array}{c}{[\mathbf{M}-\mathbf{H}]^{-}} \\
(m / z)\end{array}$ & $\mathrm{MS}^{2}$ ion fragments $(\mathrm{m} / z)$ \\
\hline Caffeic acid* & 179 & $135(100 \%)$ \\
\hline Caffeic acid-glucuronide & 355 & $179(100 \%)$ \\
\hline Caffeic acid-sulphate & 259 & $179(100 \%), 135(19 \%)$ \\
\hline 3-O-Caffeoylquinic acid & 353 & $191(100 \%), 179(43 \%), 135(9 \%)$ \\
\hline 4-O-Caffeoylquinic acid & 353 & $179(100 \%), 173(44 \%), 135(40 \%), 191(27 \%)$ \\
\hline 5-O-Caffeoylquinic acid* & 353 & $191(100 \%), 173(3 \%)$ \\
\hline Cinnamic acid * & 147 & $103(100 \%)$ \\
\hline$o$-Coumaric acid* & 163 & $119(100 \%)$ \\
\hline p-Coumaric acid* & 163 & $119(100 \%)$ \\
\hline Coumaric acid-glucuronide & 339 & $113(100 \%), 163(35 \%), 119(21 \%), 175(7 \%)$ \\
\hline Coumaric acid-sulphate & 243 & $163(100 \%), 119(14 \%)$ \\
\hline Di-hydro-caffeic acid* & 181 & $137(100 \%)$ \\
\hline Di-hydro-caffeic acid-cysteine & 300 & $213(100 \%), 135$ (76\%), $181(65 \%), 107$ (40\%) \\
\hline Di-hydro-caffeic acid-sulphate & 261 & $181(100 \%)$ \\
\hline Di-hydro-coumaric acid & 165 & $121(100 \%)$ \\
\hline Di-hydro-ferulic acid* & 195 & $177(100 \%), 136(99 \%), 151(11 \%), 175(7 \%)$ \\
\hline Di-hydro-ferulic acid-glucuronide & 371 & $195(100 \%), 113(65 \%)$ \\
\hline Di-hydro-ferulic acid-sulphate & 275 & $195(100 \%)$ \\
\hline Ferulic acid* & 193 & $178(100 \%), 134(94 \%), 149(79 \%)$ \\
\hline Ferulic acid-glucuronide & 369 & $175(100 \%), 193(42 \%), 113(40 \%)$ \\
\hline Ferulic acid-sulphate & 273 & $193(100 \%)$ \\
\hline 5-O-Feruloylquinic acid & 367 & $179(100 \%), 135(30 \%)$ \\
\hline
\end{tabular}

*Identified by comparison with the corresponding standard 
Table 3. Stability of hydroxycinnamic acids and coumaroylquinic acids and hydroxycinnamoyl aspartates enriched fractions after $24 \mathrm{~h}$ of incubation in Caco-2 and SW480 cell media without cells. Results are expressed as \% recovery respect to the initial dose.

\begin{tabular}{lcc}
\hline Compounds & $\begin{array}{c}\text { Caco-2 medium } \\
\text { \% recovery }\end{array}$ & $\begin{array}{c}\text { SW 480 medium } \\
\text { \% recovery }\end{array}$ \\
\hline \hline Standards & $100 \pm 1.57$ & $100 \pm 1.01$ \\
Cinnamic acid & $100 \pm 0.07$ & $84.7 \pm 1.44^{*}$ \\
$p$-Coumaric & $96.1 \pm 0.51$ & $96.4 \pm 0.94$ \\
$o$-Coumaric & $56.3 \pm 1.34^{*}$ & $97.2 \pm 1.44$ \\
Caffeic acid & $93.1 \pm 2.27$ & $100 \pm 0.58$ \\
Ferulic acid & $35.3 \pm 0.33^{*}$ & $63.2 \pm 2.36^{*}$ \\
5-Caffeoylquinic acid & $35.3 \pm 0.52^{*}$ & $70.8 \pm 0.42^{*}$ \\
Di-hydro-caffeic acid & $71.1 \pm 0.33^{*}$ & $69.7 \pm 1.34^{*}$ \\
Di-hydro-ferulic acid & & \\
Coumaroylquinic acids enriched & & $64.6 \pm 0.34^{*}$ \\
fractions & $56.8 \pm 1.32^{*}$ & $47.3 \pm 0.92^{*}$ \\
4-Coumaroylquinic acid & $124.2 \pm 2.06^{*}$ & \\
5-Coumaroylquinic acid & & $94.6 \pm 0.88$ \\
Hydroxycinnamoyl aspartates enriched & & $47.6 \pm 0.41^{*}$ \\
fractions & & $88.4 \pm 1.27^{*}$ \\
Coumaroyl-aspartate & $90.4 \pm 4.31$ & \\
Caffeoyl-aspartate & $57.2 \pm 0.74^{*}$ & $62.3 \pm 0.39^{*}$ \\
Feruloyl-aspartate & & \\
\hline
\end{tabular}

Hydroxycinnamic acids were tested at $200 \mu \mathrm{mol} / \mathrm{L}$. Coumaroylquinic acids and hydroxycinnamoyl aspartates enriched fractions were tested after two-fold dilution in cell media. Coumaroylquinic acids final concentration in the cell media were 36.2 and $13.9 \mu \mathrm{mol} / \mathrm{L}$ for 4-coumaroyl-quinic and 5-coumaroyl-quinic acids, respectively. Hydroxycinnamoylaspartates concentration in the cell media were $224,55.2$ and $33.1 \mu \mathrm{mol} / \mathrm{L}$ for coumaroyl-aspartate, caffeoyl-aspartate and feruloyl-aspartate, respectively.

*means significantly different from the initial amount 
Table 4. Recovery (\% of initial dose) of free hydroxycinnamic acids and their metabolites in the Caco-2 and SW480 extracellular culture medium after $24 \mathrm{~h}$ of incubation with cells.

\begin{tabular}{|c|c|c|}
\hline Compounds & $\begin{array}{c}\text { Caco-2 } \\
\% \text { of initial dose }\end{array}$ & $\begin{array}{c}\text { SW } 480 \\
\% \text { of initial dose }\end{array}$ \\
\hline \multicolumn{3}{|l|}{ Substrate } \\
\hline Cinnamic acid & $101 \pm 1.46$ & $100 \pm 1.01$ \\
\hline \multicolumn{3}{|l|}{ Metabolites } \\
\hline Coumaric acid & Traces & Traces \\
\hline Total & $101 \pm 1.46$ & $100 \pm 1.01$ \\
\hline \multicolumn{3}{|l|}{ Substrate } \\
\hline$p$-Coumaric acid & $76.3 \pm 0.73$ & $72.9 \pm 2.70$ \\
\hline \multicolumn{3}{|l|}{ Metabolites } \\
\hline$p$-Coumaric acid glucuronide & Traces & n.d. \\
\hline Cinnamic acid & Traces & n.d. \\
\hline Di-hydro-coumaric acid & Traces & $13.8 \pm 0.40$ \\
\hline Total & $76.3 \pm 0.73 *$ & $86.7 \pm 2.73$ \\
\hline \multicolumn{3}{|l|}{ Substrate } \\
\hline$o$-Coumaric acid & $63.3 \pm 0.31$ & $55.2 \pm 1.05$ \\
\hline \multicolumn{3}{|l|}{ Metabolites } \\
\hline$o$-Coumaric acid glucuronide isomer 1 & $0.55 \pm 0.02$ & n.d. \\
\hline$o$-Coumaric acid glucuronide isomer 2 & $43.6 \pm 1.11$ & n.d. \\
\hline Di-hydro-coumaric acid & n.d. & Traces \\
\hline Coumaric acid sulphate & n.d. & $32.0 \pm 0.95$ \\
\hline Total & $107 \pm 1.15$ & $87.2 \pm 1.42 *$ \\
\hline \multicolumn{3}{|l|}{ Substrate } \\
\hline Caffeic acid & $46.4 \pm 0.40$ & $57.7 \pm 2.62$ \\
\hline \multicolumn{3}{|l|}{ Metabolites } \\
\hline Ferulic acid & $3.08 \pm 0.07$ & n.d. \\
\hline Coumaric acid & Traces & Traces \\
\hline Caffeic acid glucuronide & $0.11 \pm 0.01$ & n.d. \\
\hline Caffeic acid sulphate & n.d. & $0.24 \pm 0.02$ \\
\hline Total & $49.6 \pm 0.41^{*}$ & $57.9 \pm 2.62 *$ \\
\hline \multicolumn{3}{|l|}{ Substrate } \\
\hline Ferulic acid & $82.0 \pm 0.21$ & $48.2 \pm 1.00$ \\
\hline \multicolumn{3}{|l|}{ Metabolites } \\
\hline Ferulic acid glucuronide & $21.9 \pm 0.82$ & n.d. \\
\hline Di-hydro-ferulic acid & Traces & n.d. \\
\hline Ferulic acid sulphate & $4.01 \pm 0.08$ & $2.90 \pm 0.24$ \\
\hline Total & $107 \pm 0.85$ & $51.1 \pm 1.03^{*}$ \\
\hline \multicolumn{3}{|l|}{ Substrate } \\
\hline 5-Caffeoylquinic acid & $41.2 \pm 1.50$ & $45.5 \pm 0.41$ \\
\hline \multicolumn{3}{|l|}{ Metabolites } \\
\hline 3-Caffeoylquinic acid & $14.5 \pm 0.21$ & $2.52 \pm 0.13$ \\
\hline 4-Caffeoylquinic acid & $19.7 \pm 1.90$ & $43.1 \pm 1.02$ \\
\hline Caffeic acid & $0.27 \pm 0.01$ & Traces \\
\hline 5-Feruloylquinic acid & $17.0 \pm 0.57$ & n.d. \\
\hline Total & $92.7 \pm 2.50$ & $91.1 \pm 1.11 *$ \\
\hline \multicolumn{3}{|l|}{ Substrate } \\
\hline Di-hydro-caffeic acid & $30.7 \pm 0.27$ & $76.9 \pm 0.95$ \\
\hline
\end{tabular}




\section{Metabolites}

Di-hydro-ferulic acid

Traces

$0.87 \pm 0.01$

n.d.

n.d.

$31.6 \pm 0.27$

$46.9 \pm 1.45$

$0.53 \pm 0.01$

$0.22 \pm 0.01$

$0.71 \pm 0.01$

$48.4 \pm 1.45^{*}$

Total

Ferulic acid

Di-hydro-ferulic acid sulphate

\section{Substrate}

4-Coumaroylquinic acid

5-Coumaroylquinic acid

Metabolites

3-Coumaroylquinic acid

Coumaroylquinic acid glucuronide

Di-hydro-coumaric acid

Coumaric acid glucuronide

Coumaric acid

Total

Substrate

Caffeoyl-aspartate

Coumaroyl-aspartate

Feruloyl-aspartate

Metabolites

Caffeic acid

Ferulic acid

Coumaric acid
$25.9 \pm 0.19$

$26.6 \pm 0.11$

$30.4 \pm 0.15$

$2.29 \pm 0.04$

$3.26 \pm 0.09$

$6.67 \pm 0.12$

$3.47 \pm 0.02$

$98.6 \pm 0.31$

$7.62 \pm 0.95$

$27.2 \pm 2.87$

$9.56 \pm 1.08$

$1.55 \pm 0.21$

$0.42 \pm 0.02$

$0.41 \pm 0.02$

$46.8 \pm 3.22 *$ n.d.

n.d.

$23.8 \pm 1.12$

$4.77 \pm 0.12$

$105 \pm 1.47$

$63.2 \pm 2.17$

n.d.

n.d.

$2.98 \pm 0.03$

$66.2 \pm 2.17$

$31.0 \pm 0.64$

$20.5 \pm 2.08$

$23.9 \pm 0.24$

n.d.

n.d.

n.d.

Traces

$75.4 \pm 2.19 *$

$42.6 \pm 8.78$

$8.31 \pm 0.58$

$9.54 \pm 0.25$

$0.52 \pm 0.02$

n.d.

n.d.

Hydroxycinnamic acids were tested at $200 \mu \mathrm{mol} / \mathrm{L}$. Coumaroylquinic acids and hydroxycinnamoyl aspartates enriched fractions were tested after two-fold dilution in cell media. Coumaroylquinic acids final concentration in the cell media were 36.2 and $13.9 \mu \mathrm{mol} / \mathrm{L}$ for 4-coumaroyl-quinic and 5-coumaroyl-quinic acids, respectively. Hydroxycinnamoylaspartates concentration in the cell media were $224,55.2$ and $33.1 \mu \mathrm{mol} / \mathrm{L}$ for coumaroyl-aspartate, caffeoyl-aspartate and feruloyl-aspartate, respectively.

n.d. means not detected

*means significantly different from the amount recovered after incubation with cell-free media (Table 3). 
Table 5. Mass spectral characteristics of compounds identified in the coumaroyl quinic acids and hydroxycinnamoyl aspartates enriched extracts

\begin{tabular}{|c|c|c|c|}
\hline Peak & Compound & $\begin{array}{c}{[\mathrm{M}-\mathrm{H}]^{-}} \\
(\mathrm{m} / \mathrm{z})\end{array}$ & $\mathrm{MS}^{2}$ ion fragments $(\mathrm{m} / \mathrm{z})$ \\
\hline \multicolumn{4}{|c|}{ Coumaroylquinic acids enriched fraction } \\
\hline 1 & 3-Caffeoylquinic acid & 353 & $191(100 \%), 179(43 \%), 135$ (9\%) \\
\hline 2 & 4-Caffeoylquinic acid & 353 & $179(100 \%), 173(44 \%), 135$ (40\%), $191(27 \%)$ \\
\hline 3 & 4-Coumaroylquinic acid cis & 337 & $173(100 \%), 163(6 \%)$ \\
\hline 4 & Roseoside & 431 & $385(100 \%), 153(11 \%), 223(6 \%)$ \\
\hline 5 & 4-Coumaroylquinic acid trans & 337 & $173(100 \%), 163(4 \%)$ \\
\hline 6 & 5-Coumaroylquinic acid trans & 337 & $191(100 \%), 173(3 \%), 163(2 \%)$ \\
\hline 7 & 5-Coumaroylquinic acid cis & 337 & $191(100 \%), 163(7 \%), 173(2 \%)$ \\
\hline \multicolumn{4}{|c|}{ Hydroxycinnamoyl aspartates enriched fraction } \\
\hline 1 & Caffeoyl aspartate isomer 1 & 249 & $\begin{array}{r}132(100 \%), 179(79 \%), 227(36 \%), 276(34 \%), \\
250(14 \%)\end{array}$ \\
\hline 2 & Caffeoyl aspartate isomer 2 & 249 & $132(100 \%), 276(54 \%), 179(31 \%), 232(2 \%)$ \\
\hline 3 & Coumaroyl aspartate isomer 1 & 278 & $132(100 \%), 163(48 \%), 234(19 \%), 119(3 \%)$ \\
\hline 4 & Feruloyl aspartate isomer 1 & 308 & $193(100 \%)$ \\
\hline 5 & Coumaroyl aspartate isomer 2 & 278 & $132(100 \%), 163(74 \%), 119(24 \%), 234(6 \%)$ \\
\hline 6 & Feruloyl aspartate isomer 2 & 308 & $193(100 \%), 149(65 \%), 132(35 \%)$ \\
\hline 7 & (Epi)catechin-O-sulphate & 369 & $289(100 \%), 245(9 \%), 125(9 \%)$ \\
\hline 8 & $\begin{array}{l}\text { 12-hydroxy jasmonic acid sulphate } \\
\text { isomer } 1\end{array}$ & 305 & $97(100 \%), 225(35 \%)$ \\
\hline 9 & $\begin{array}{l}\text { 12-hydroxy jasmonic acid sulphate } \\
\text { isomer } 2\end{array}$ & 305 & $97(100 \%), 225(33 \%)$ \\
\hline
\end{tabular}

Coumaroylquinic acids enriched fraction was obtained from in vitro digested cherry as reported in material and methods section. Peaks are numbered as reported in Figure 3C. Hydroxycinnamoyl aspartates enriched fraction was obtained from in vitro digested dark chocolate as reported in material and methods section. Peaks are numbered as reported in Figure 4D. 
Figure 1
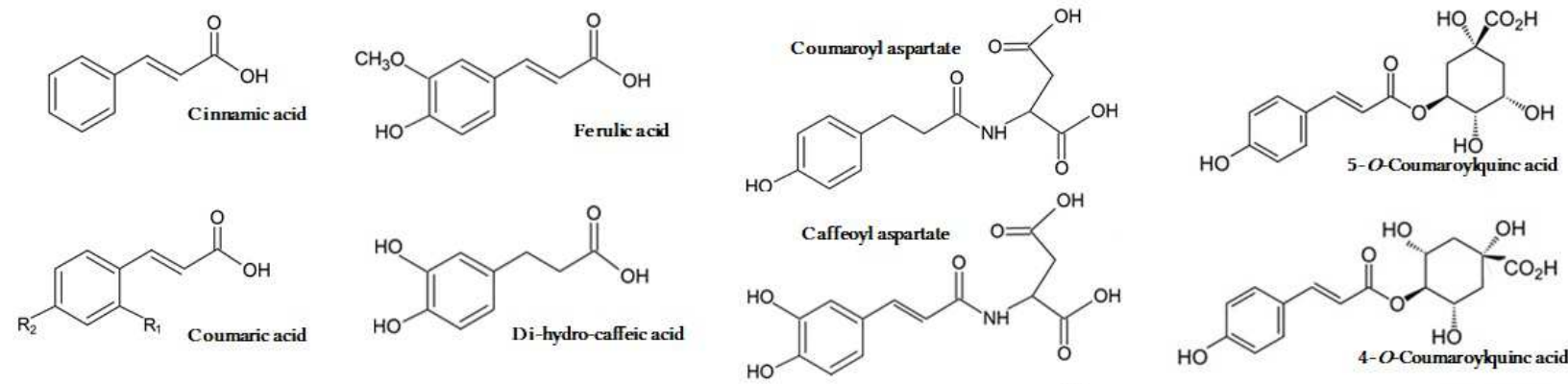<smiles>O=C(O)/C=C/c1ccc(O)c(O)c1</smiles>

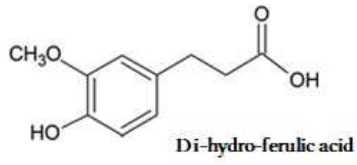<smiles>COc1cc(/C=C/C(=O)NC(CC(=O)O)C(=O)O)ccc1O</smiles>

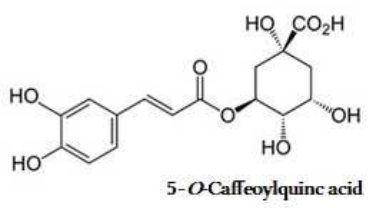


Figure 2
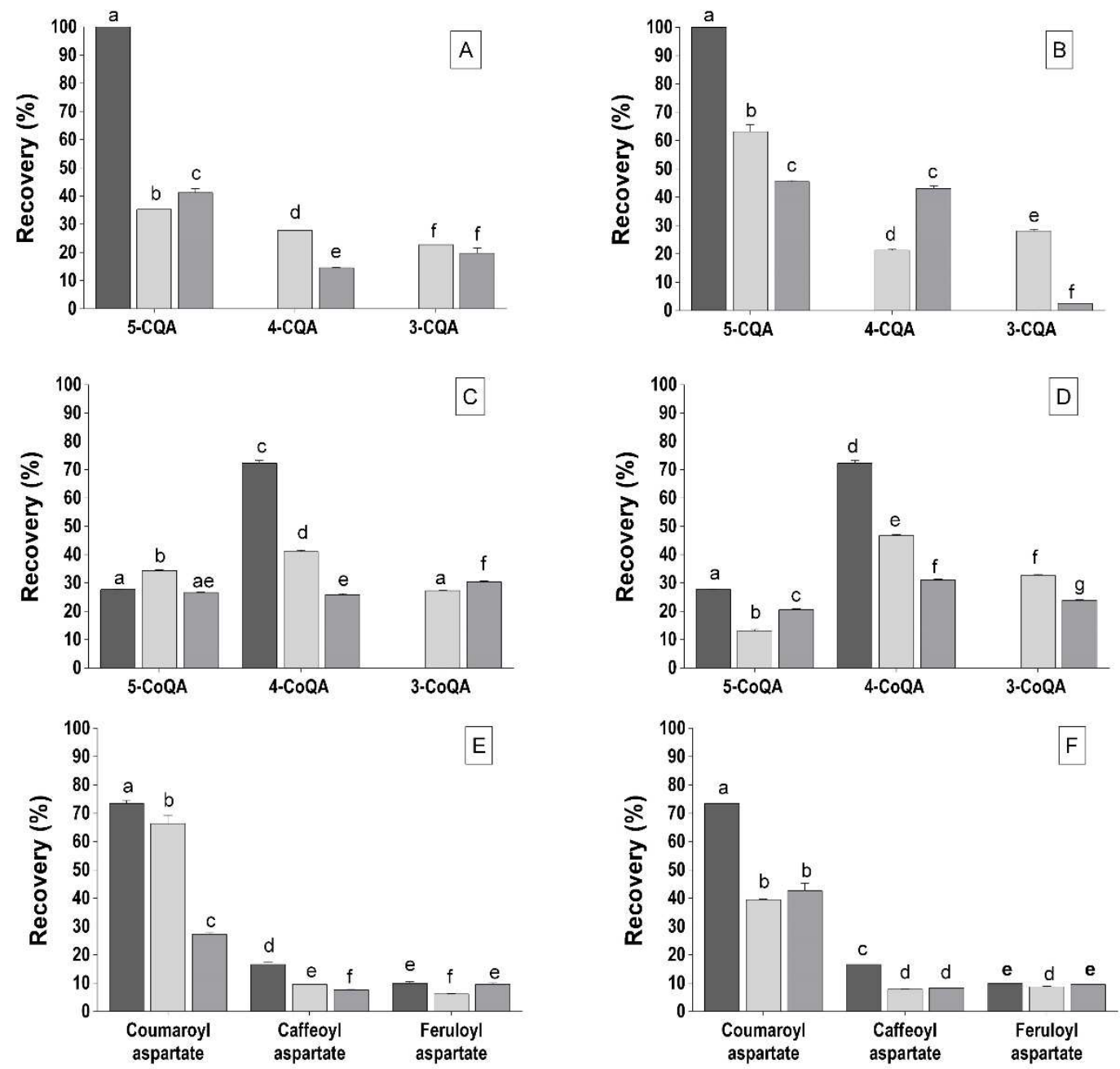
Figure 3
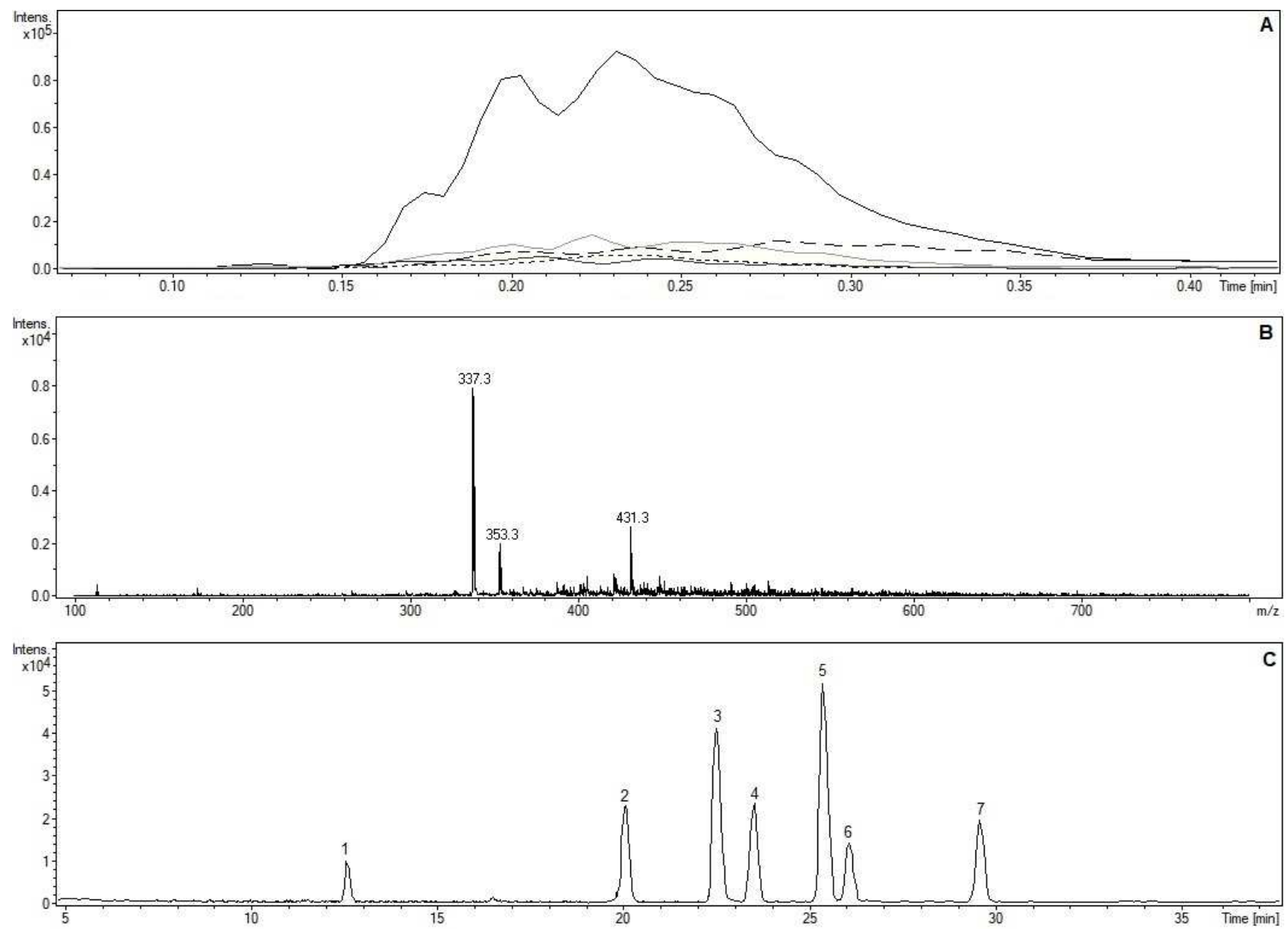
Figure 4
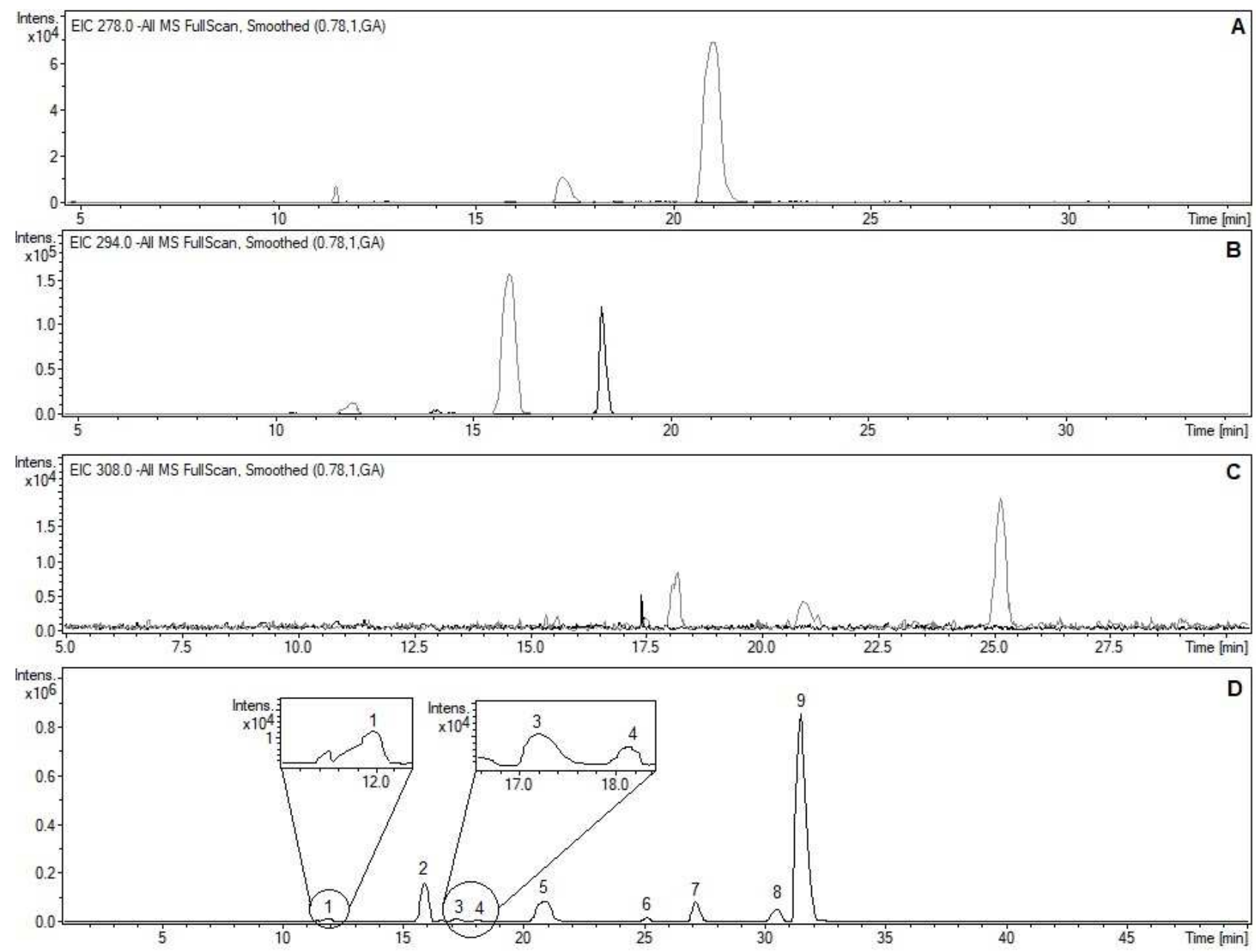


\section{Figure 5}

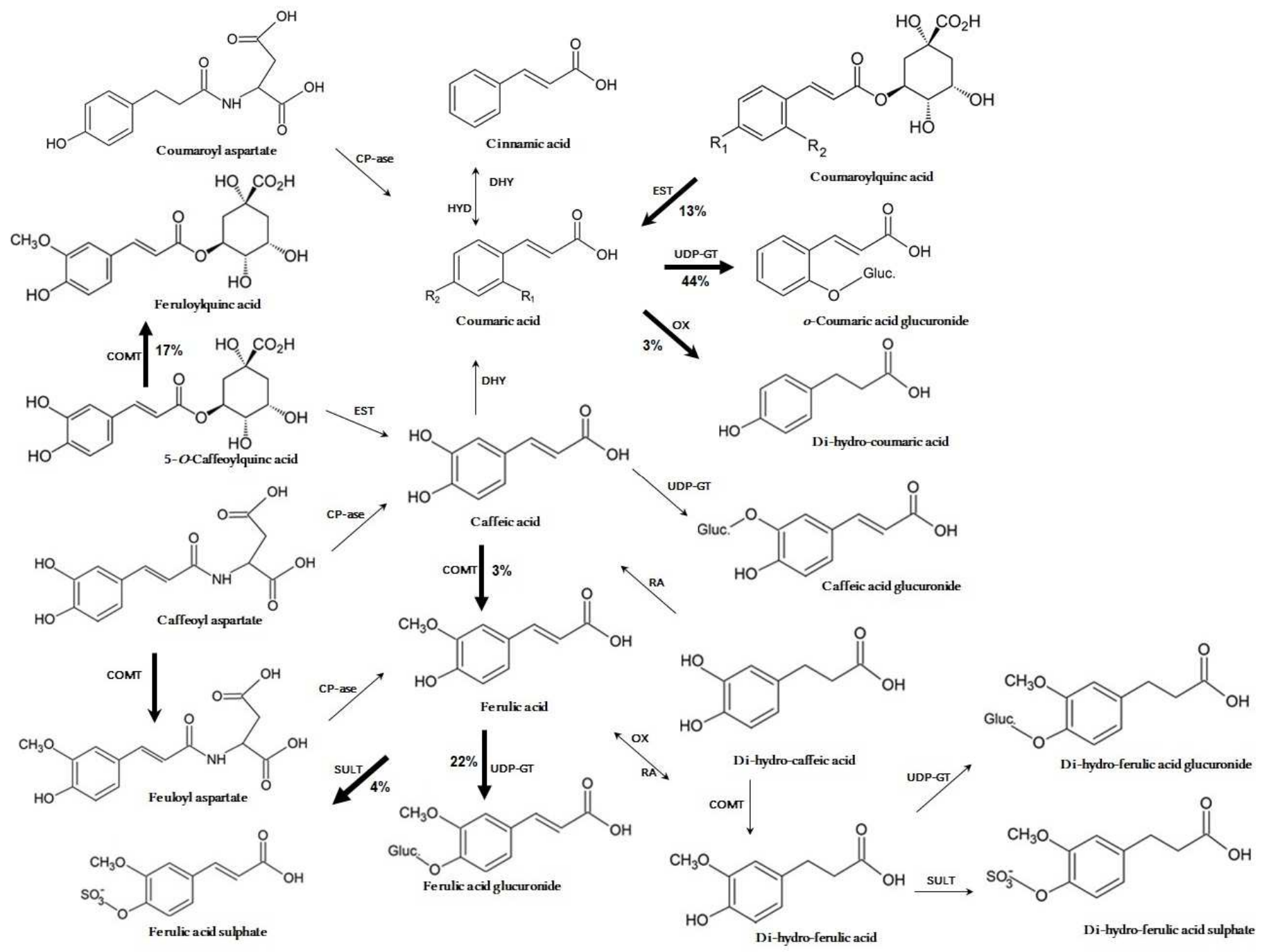


Figure 6

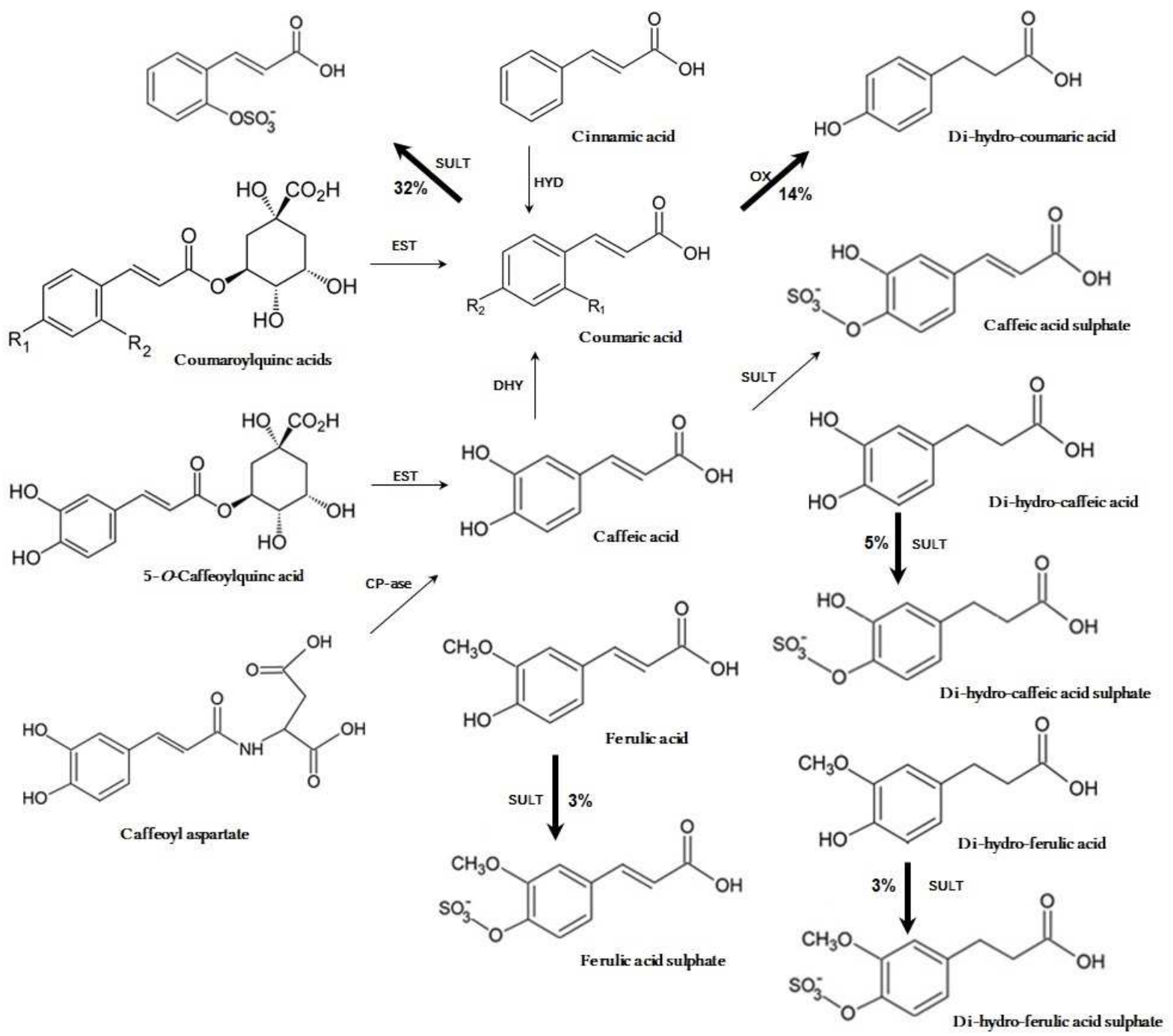




\section{Graphic for table of contents}

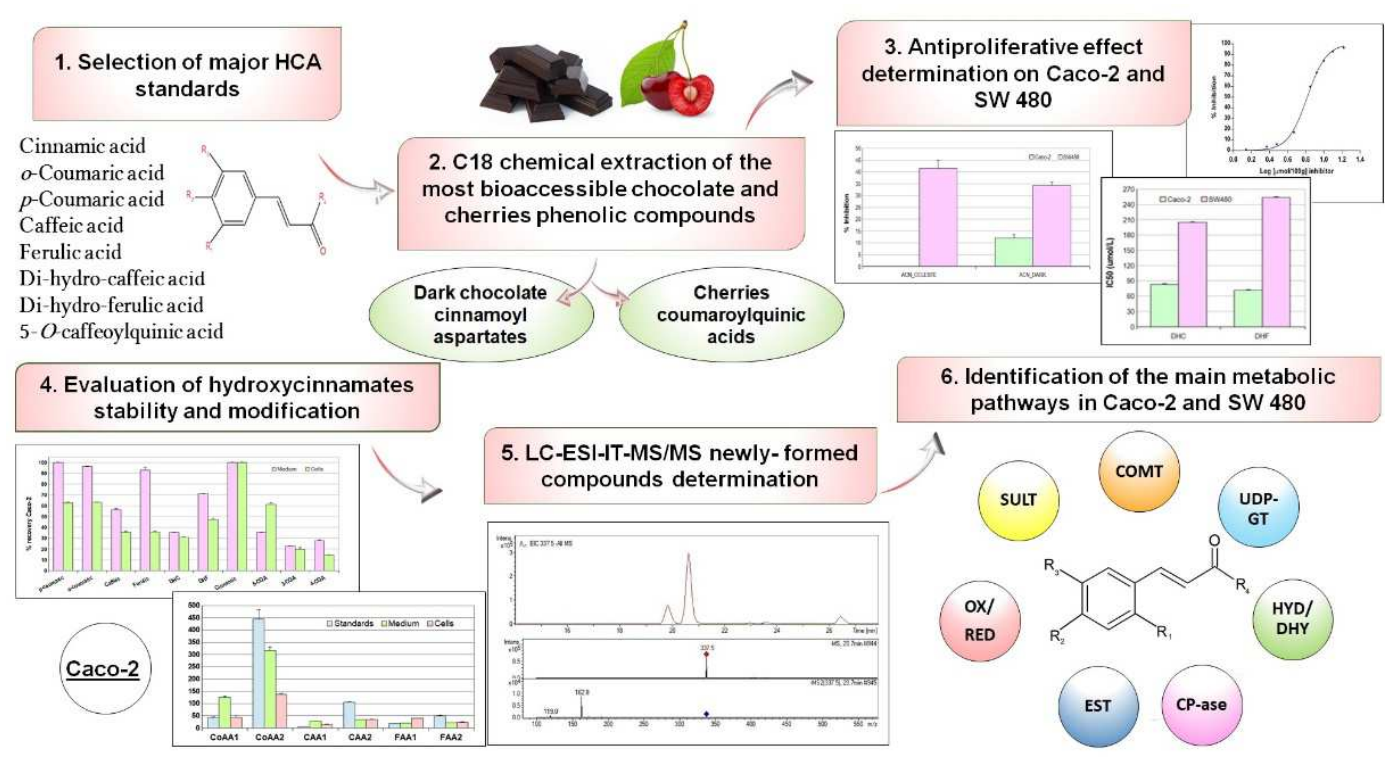

